......... Jorge Feres Kfuri

\title{
SOBRE A PREPARAÇÃO DE UM SISTEMA PARA MEDIDA DO EFEITO ELETRO-ÓTICO EM CRISTAIS E RESULTADOS OBTIDOS, PARA CENTRO "F", EM ALGUNS HALOGENETOS ALCALINOS
}

Dissertaçáo apresentada ao Instituto de Fisica e Química de S. Carlos para obtençáo do título de MESTRE EM FISICA

$$
\text { I F Q S C }
$$

Departamento de Flsica e Clencias dos Materiais SAO CARLOS 
Jorge Feres Kfuri

\title{
SOBRE A PREPARAÇÃO DE UM SISTEMA PARA MEDIDA DO EFEITO ELETRO-ÓTICO EM CRISTAIS E RESULTADOS OBTIDOS, PARA CENTRO "F", EM ALGUNS HALOGENETOS ALCALINOS
}

\author{
Dissertação apresentada ao \\ Instituto de Fisica e Quimica de \\ S. Carlos para obtenção do título \\ de MESTRE EM FISICA
}

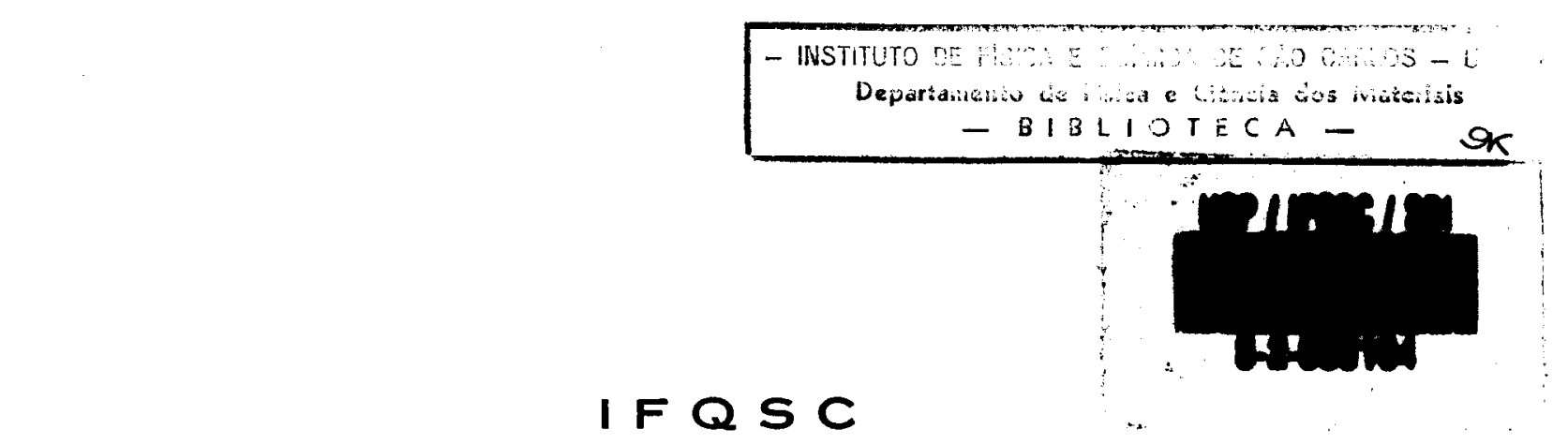

Departamento de Fisica e Ciencias dos Materiais SAO CARLOS

1974 
A meu mano: José Feres Kfur1

A meus fllhos: Renato

Zezé

Patrícia 


\section{AGRADECIMENTOS}

Ao Professor Milton Ferreira de Souza, que, mais que um esclarecido orientador, fol tambëm um grande amigo.

Ao Professor Renē Robert pelas discussōes e sugestōes muito valiosas.

Aos Professores dos Cursos de Pós-Graduaçäo.

Ao Professor Doutor Celso Volpe, Digníssimo Diretor da Faculdade de F1lo sofia, Ciēncias e Letras de Sēo José do Rio Preto, p:lo grande apolo e incentivo racabidos.

Ao Sr. Domingos Alello pelo seu auxillo nas expertênclas.

Ao Sr. Carlos Fauvel, pelo crescimento e coloraçäo de cristals.

Ao Sr. Carrá, pela assistèncla técnica proporcionada.

Aos técnicos da oficina, pela construção de parte do equipamento.

Aos demais funcionários do Departamento de Físjca e Ciéncla dos Materiais do Instituto de Física e Ruímica de São Carlos - USP, que sempre, de algum modo, contribuiram para a maior facllidade da realisaçāo do presente trabaIho.

A todos apresento, sinceramente, o mais profundo dos agradecimentos. 
Patrocinadores.................................................... 1

Resumo............................................................ ii

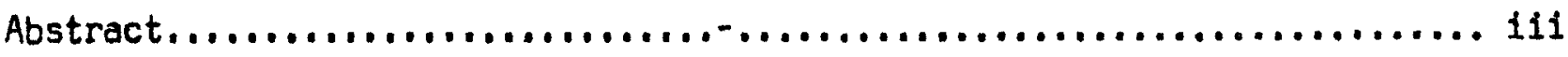

CAPITULD I. - INTRODUÇAO

I.1. - A importāncia do estudo de defeitos e Impurezes sot cristais................................... 1

I.2. - Centros de cor $. \ldots \ldots \ldots \ldots \ldots \ldots \ldots \ldots \ldots \ldots \ldots \ldots \ldots,{ }_{1}$

I.3. - o centro $F$ em halogenetos alcalinos................ 3

CAPITULO II. - TEORIA

II.1. - O efeito Stark em centro F.................... 7-A

II.2. - Teoria do efeito Stark....................... 9

II.3. - O método dos momentos.......................... 12

II.4. - Previsöes teóricas pelo "método dos momentos"........ 14

II.5. - Resultados experimentais obtidos por Chiarotti e outros para o centro $F$ em KCl........................ 17

II.6. - Forma de comparação entre as previsōes teóricas e resul tados experimentais........................... 19

CAPITULD III. - PARTE EXPERIMENTAL

III.1. - Consideraçōes básicas sobre a técnica experimental....21-A

III.2. - Valores ótimos para as dimensōes da amostra e concentraçào de centros de cor..................... 21

III.3. - Aparelhagem utilisada para efeito Stark........... 21

III.4. - Preparação das amostras....................... 23 
III.5. - Implicaçōes da tecnica utilizada nos valores das medi das.................................... 24

III.6. - 0 criostato, montegen da amostra a detalhes de operação 27

III.7. - Ruidos.................................... 29

capitulo IV. - Resultados, conclusões e sugestōes

IV.1. - Resultados obt1dos.......................... 31

IV.2. - Discussão dos resultados e conclusöes.............. 34

IV.3. - Sugestōes para trabalhos futuros............ . . . . . 35

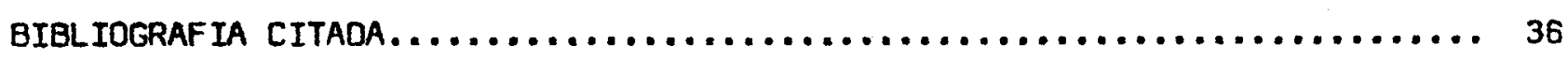

LEGENDAS DAS fIGURAS. ................................ 37 6 38

FIGURAS.

39 e seguintes 
Este trabalho foi possivel efetuar-se graças às instituiçōes que patroc1 nam o Departamento de Física a Ciéncla das Materiais do Instituto de física e Química de São Carlos-USP : - CAPES, BNDE-FUNTEC, CNPq, FAPESP. 
RESUMO

A montagen de um sistema que permite a detecção de modulaçāo no coefi ciente de absorção ótica, devido ao campo elétrico aplicado, foi concluída. A máxima sensibilidade atingida foi de $\frac{\Delta K}{K}=1,5 \times 10^{-6}$ com resolução, em com primento de onda, de $3 \mathrm{~mm}$.

o efeito Stark de 2. ordem, na frequência dupla da do campo elétrico aplicado fol medido para o centro $F$ em KCl e $\mathrm{KBr}$ e comparado com previsöes teöri cas. Os valores obtidos para o $\mathrm{KCl}$ coincidem com os de Chiarotti, o que confirma o bom funclonamento do sistema, e diferem dos valores calculados teóricamente. Essa diferença é atribuida à correçāo do campo local.

Os valores obtidos experimentalmente para a variação relativa do coefi ciente de absorçāo foram:

$$
\begin{aligned}
& \text { para KC1: } \frac{\Delta K}{K}=2.93 \times 10^{-5}\left(78^{\circ} K\right) \\
& \text { para KBr: } \frac{\Delta K}{K}=2.85 \times 10^{-5}\left(78^{\circ} K\right)
\end{aligned}
$$




\section{A B S T R A C T}

The assembly of a system which allows the detection of modulation in the coeficient of optical absorption, due to the apliled electrical field, was com pleted. The maximum sensitivity achieved was $\frac{\Delta K}{K}=1,5 \times 10^{-6}$ with resolution. in wave length, of $3 \mathrm{~nm}$.

The Stark effect of second order, in the frequency twice as that of the applied electrical field was measured for the center $F$ in $K C l$ and $K B r$ and compe red with theoretical previsions. The values obtained for $\mathrm{KCl}$ coincide with those of Chiarotti's, which confirms the good functioning of the system, and differ from the values calculated theoretically. This difference is ascribed to the correction of the local field.

The values obtained experimentally for the relative variation of the coe ficient of absorption were:

$$
\begin{aligned}
& \text { for } K C l: \frac{\Delta K}{K}=2,93 \times 10^{-5}\left(78^{\circ} \mathrm{K}\right) \\
& \text { for } K B r: \frac{\Delta K}{K}=2,85 \times 10^{-5}\left(78^{\circ} \mathrm{K}\right)
\end{aligned}
$$




\section{CAPITULO I. INTRODUCAO}

\section{I.1. - A IMPORTANCIA DO ESTUDO DE DEFEITOS E IMPUREZAS EM CRISTAIS.}

Aos defeitos a impurezas da rède damos o nome geral de imperfelçōes dos cristais.

Uma imperfeição é qualquer desvio ou diferença que a rêde cristalina apresenta em relação à uma estrutura ou rêde perfeitamente regular.

Todos os cristais reais são, em malor ou menor grau, imperfeitos em algum aspécto, porém a natureza das imperfeiçōes tem podido ser melhor explicada em alguns tipos de sólidos que em outros. É assim qua uma grande parte do trabalho realisado neste campo se refere aos haloganetos alcalinos, halogenetos de prata, germanio, silicio, cobre e estanho.

Os problemas relacionados cam as imperfeiçōes constituem um dos temas de Investigação mais importantes da Física do Estado Sólido. Este fato pode ser explicado pela observação de que um bom nümera de importantes propriedades dos sólidos são determinadas mais pela natureza das imperfeições do que pela natureza do próprio cristal, que atua simplesmente como um veículo de imperfe1 çōes. Assim, por exemplo, a condutividade dos semi-condutores pode depender in teiramente de pequenos traços de impurezas químicas. A cor de muitos cristals é devida a imperfeições. Sua luminescència está quase sempre ligada à presença de impurezas. A difusão nos sólidos pode ser acelerada enormemente pela presen ça de defeitos da rêde ou impurezas. As propriedades mecânicas e plásticas dos sólidos são controladas geralmente por deslocaçōes, que representam um tipo es pecial de defeitos.

I. 2 - CENTROS DE COR.

Os cristais puros de halogenetos alcalinos são transparentes à regiäo 
visivel do espectro. Esta transparencia persiste inciusive à temperaturas ele vades, em que se produz uma concentraçáo substancial de vacancias em equ111 brio, desde que nào haja decomposiçäo químice.

Existem diversas formas de colorir os cristais. Uma delas consiste ne Introduçào de diversas impurezas químices, tais como lons de elementos de transiçäo, com niveis energéticos excitados separados do estado fundamental por uma frequēncla ótica. Isto significa que os lons cujos sals sào normolmen te coloridos podem, por sua vez, colorir os cristals de halogenetos alcalinos.

Se sabe tambēm, desde há cerca de com anos, que é possivel colorir os cristals introduzindo un excesso estequiométrico do cation, por sxemplo aque cendo o cristal em presença de vapor de metal alcalino $\theta$, em seguida, esfrian do rapidamente.

Assim, quando um cristal de cloreto ds södio é aquecido em presença de vapor de sódio ele toma uma cor amarelada; o cloreto de potássio, aquecido em presença de vapor de potássio toma uma cor violácea, até uma profundidade que pode ser grande se a pressāo do vapor é suficlente e a temperatura slevada.

Também é possível colorir a obscurecer os cristais por outras mëtodos. tals como a Irradiaçäo por raios X e ralos gama, bombardelo eletrōnico, assim cono oletrólise.

Quando um cristal é colorido desse modo, se diz que possue "centras de cor". Estes centros sào imperfeiçōes da rēde que absorvem luz.

A absorçāo dos centros de cor observada como bandas de emplitudo bestante grande, em contraste com as linhas do espectro atómico.

Vários modelos tèm sido propostos para as configurą̧öes iónicas e eletrōntca das imperfaiçēes responsäveis por essas bandas.

Estudos tiplcos que têm sido usadas para vorificar ou regeitar esses modelos incluem a absorçāo ötica, dicrolsmo. rassonancla de spin do eletron 
(ESR), dupla ressonancia eletrônica a nuclear (ENDOR). luminescencia a perdas dielétricas. Em 1958, Overhauser a Rüchardt (1) sugeriram o uso do efeito Stark IInear (LSE) para detarminar se um centro de cor que exibe dicroismo apres:enta Inversäo de slmetrio. O efelto Stark, neste caso,é mals propriamente chamado efelto eletro-ötico ou efeito eletrocrolco, pelo fato de que, neste caso, a apli caçāo de um forte campo elétrico produz uma absorçäo anisotrōplca. Eles pretenderam determinar um efeito nas bandas $M$ a $R$, em KCl e NaCl, mas falharam. Em 1965. Hefiry Schnattery e Slichter (2) analisaram o efelto de perturbaçöes externas nas formas das curvas obtidas para as bandas de absorção. Eles consideraram - caso do efeito de um campo elétrico no centro F. Como o centro F tem simetria cüblca nāo existe o efeito Stark 11near, mas deverla existir um efeito quadrático.

Em novembro de 1966 Chiarott1, Grassano e Rosel (3) relataram a observaçäo dessa efeito, usando um campo elétrico ac.

o objetivo do presente trabalho alëm de descrever a preparaçăo de um sis tema a ser ut111sado para o estudo de centros de cor en cristals mixtos através do efeito Stark, estudo este até agora alnda nāo efetuedo, e os problemas e 1 mplicaçöes do uso de tal sistema, pretende tembém apresentar os resultados obtidos da medida do efeito Stark de centros F em KCl a KBr, efetuados com tal sistema. Os resultados obtidos mostram que o KCl e o KBr apresentam praticamente o mesmo valor para a varlaçäo relativa do coeficiente de absorçāo, e este resulta do comum parece ser o efeito da Influencia de presença do ion alcalino comum, o que poderá ser confirmado com medidas a serem efetliadas em KI e outros halogene tos de ion alcalino comum.

\section{I.3 - O CENTRO F EM HALOGENETOS ALCALINOS.}

o tipo mais simples de centro de cor é o centro F ( F de "Farbe", pala - 
vra alemä que significa "cor" ).

Os centros F sāo produzidos geralmente por aquecimento em excesso de vapor alcalino ou por irradiaçäo com raios $x$.

No processo de criaçẽo do centro F. un àtomo alcalino en excesso acupa a posiçāo de uma primitiva vacancia positiva a o eletron originado da lonisaçào desse átomo passa a ligar-se à uma vacancio negativo.

Uma vacancia anionica en cristais lonicos representa un ponto com carga positiva não compensada a que pode assim capturar um eletron formando um centro F. Deste modo, o centro F pode ser considerado como sendo anälogo à um étamo de hidrogênio num melo polarisāvel, o que faz dele un caso simples que gerve de mo delo para imperfelçōes eletrônicas mais complicadas axistentes nos sólidos.

A principal banda de absorçäo assaciada ao centro $F$ i a chamada bonda F". A posiçāo e largura da banda $F$ depende, de modo sistemático. da constante da rêde do cristal e também da temperatura. Nos halogenetos alcalinos o comprimento de onda, $\lambda_{m}$ ( em $A$ ), no qual ocorre o pico da banda $F$, em temperatura ambiente ( cerca de $300^{\circ} \mathrm{K}$ ) está relacionada, emplricamente, com o valor (em A) da distâncla de separaçāo entre os vizinhos mals próximos da rêde pela conhec1da "relação de Ivey-Mallow" (4), que é:

$$
\lambda_{m}=703 d^{1,84}\left(\lambda_{m} \text { od en } \AA\right.
$$

A medida que diminue a temperatura da amostra, a banda $F$ val ficando mals estreita e desloca-se para o lado dos menores comprimentos de onda.

Pelo fato de ser considerado como de estrutura multo simples, o centro F tem sido estudado de modo amplo, tanto sob o ponto - de viste ixi...énportimontál como teórico. Alśm disso, acredita-se que o mesmo é um dos componentes de vérios outros centros.

As propriedades do centro $F$ sāo determinadas pela Interaçāo do . elatron capturado com os lons da réde. 
Para calcular teoricamente a posiçāo e forma da banda $F$, sua

com a temperatura e a energla térmica de ionizaçào do seu estado excitado são necessärias aproximaçōes simplificadoras. Uma revisäo dos modelos que ut1l1sam diversas aproximaçōes ä apresentada por Gourary e Adrian (5), Schulman e Compton (6) e Markham (7).

A figura 1. mostra a banda $F$ produzida por cristais coloridos de KBr, apesar dos cristals puros serem mais ou menos transparentes, desde regiäo pröxima dos $50 \mu(0,025 \mathrm{eV})$ até as vizinhanças de $6.5 \mathrm{eV}$, no ultravioleta, os cristais coloridos aditivamente contèm uma forte banda $F$ em $2,1 \mathrm{eV}$.

Um cálculo dos auto-estados eletrōnicos do centro f depende da escolha do modelo de potencial usado ( para uma revisão adequada das vārias aproxima -çöes ut1lisadas veja a referéncia (8)). Mas independentemente da escolna feita, as soluçōes do problema do centro F são dadas por funçōes de onda do tipo das do átomo de hidrogēnio. Na absorçẽo, a banda $F$ pode ser descrita como uma transiçāo entre o estado fundamental is e o estado excitado $2 p$, triplamente degene rado. Atualmente acredita-se, de modo geral, que excitaçōes para estados 3p, 4p ou outros $p$ de ordem mals elevada dāo origem à banda $K$ do centro $F$, que pode ser vista na figura I como uma pequena saliencia no lado de alta anergla da banda Apesar do espectro da figura 1 ter sido obtido na temperatura de $10^{\circ} \mathrm{K}$ apresenta uma certa largura. devida às vibraçōes dos ions circundantes. Apesar de alar gar-se e sofrer um deslocamento para o lado dos maiores comprimentos de onda, quando a temperatura aumenta, a ārea total sob a curva da banda $F$ permanece aproximadamente independente da temperatura, a não ser que o cristal seja levado a temperaturas tão altas quanto $600^{\circ} \mathrm{C}$ por periodo relativamente prolongado, o que produz o desaparecimento da banda $F$.

Bandas de absorção muito fracas, designados por $L_{1}, L_{2}$ e $L_{3}$ são indicadas na figura 1 na região entre 3,0 e 5,0 eV. Estas bandas estāo também direta- 
mente associados com a banda $F$, visto comosua absorção depende da intensidade da absorção da banda $F$ e $\dot{e}$ independente do processo de produção dessa banda.

As bandas $L$ näo săo ainda multo bem compreendidas, mos scredita-se que elas săo motivadas por estados de excitaçāo ainda mals altos do centro F, possi velmente assoclados a bandas mais elevadas do próprio cristal.

Existe ainda uma outra banda de absorção, a banda $\beta$, estreitamente ligada aos centros F. Esta banda pode ser vista na figura 1 próximo de 6,5 eV. Esta banda também aumenta em proporção com o aumento de absorção da banda F. Ela é creditada à excitons produzidos pela absorção de um foton na vizinhança imediato de um centro F. 
CAPITULO II.

IEORIA

\section{II.1. - Q EFEITO STARK EM CENTRO F.}

Devido à sua simplicidade, o centro $F$ tornou-se um sistema modelo para muitos estudos teóricos e experimentais, as quals, alèm de terem permitido obter um detalhado conhecimento sobre esse próprio centro de cor, tèm contribuldo consideravelmente para uma melhor compreensão de outras imperfelçōes eletrōn cas de sólidos em geral.

Não obstante a sua simplicidade, o centro $F$ apresenta certas dificulde des ou limitações tanto para seu estudo teórico como experimental. Por exemplo, - seu comportamento completamente isotrópico em todas as propriedades óticas nào permite o estudo dos efeitos específicos dos 1ons vizinhos. Entretanto, pela aplicação de uma perturbação numa direção determinada, poderemos reduzir a simetria cúbica do centro e obter conhecimentos que näo seriam possiveis pela Investigação do sistema não perturbado. 
Uma maneira de obter um centro $F$ perturbado desse mado consiste, por e xemplo, na aplicação de campos elétricos externos, os quais, limitados por parā metros experimentais, como por exemplo a tensão de ruptura, resultam em froces perturbaçōes.

0 estudo experimental dos efeitos dessas perturbaçōes externas pode ser correlacionado com as caracteristicas do sistema, através dos estudos teóricos realisados sobre o assunto por Henry Schnatterly e Slichter (2), cujas linhas gerais a resultados principais apresentaremos adiante (tóplcos II.3 e II.4).

0 efeito Stark ou efeito eletro-ótico do centro $F$ em $K C 1$ fol observado pela primeira vez em novembro de 1966 por Chiarott1, Grassano e Rosel (3). 0 efeito fol observado na absorção, sob temperatura do nitrogênio 1fquido, pela aplicação oo cristal de um campo elétrico ac de frequência $v$ a detectando a modu laçāo, sọ frequēncia $2 v$ de um felxe de luz monocromätica atravessando o cristal perpendicularmente ao campo. As medidas foram feitas com luz não polarisada visto como havia sido verificado que nenhum efeito é detectado com luz polarisa da perpendicularmente ao campo elétrico externo.

A avellação do efeito Stark é feita através da determinaçäo da variação do cosficlente de absorçäo da luz para cada comprimento de onda.

Sendo $I_{0}$ a intensidade da luz incidente a I a intensidade da luz emergen te da amostra, de acordo com a les de Bourguer, temos

$$
I=I_{0} e^{-K x}:
$$

$K$ é o cosficiente as absorção $a x$ a espessura de amostra atravessada pela luz.

Aplicando-se um campo elétrico de intensidade $f$ ao cristal o coeficiente de absorção passará a ser $K+\Delta K$ a a intensidade do feixe emergente será

$$
I_{f}=I_{0} e^{-(K+\Delta K) x} \quad(\text { II }-2)
$$

ande $\left(\Delta K=K_{f}-K\right)$ 
De (II-1) \& ( II-2) temos:

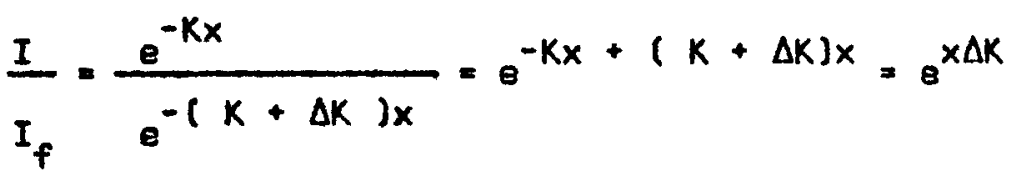

$\therefore \ln \frac{I}{I_{f}}=x \Delta K$

Considerando que $\frac{\ln a}{a-1}=1-\frac{a-1}{2}+\frac{(a-1)^{2}}{3}-\ldots$

- sendo $\frac{I}{I_{f}}=a$. como $I$ é musto aproximadamente igual a $I_{f}$, de acordo cam a experténcla, ou seja, como o valor de a é praticamente 1 resulta que $\frac{\ln a}{a-1}=1$ $\therefore$ In $a=a-1 \quad \therefore \ln \frac{I}{I_{f}}=\frac{I}{I_{f}}-1=\frac{I-I_{f}}{I_{f}}$ ou seja, sendo $\Delta I=I_{f}-I$ te mos

$$
\ln \frac{I}{I_{f}}=-\frac{\Delta I}{I}
$$

De $($ II -3$)$ e (II -4$)$ resulta que $\frac{\Delta I}{I}=-x \Delta K$

$\therefore \Delta K=-\frac{1}{x} \frac{\Delta I}{I}$

( II -5)

Por outro lado, considerando que $K=\frac{1}{x} \ln \frac{I_{0}}{I} \quad \therefore K=\frac{20}{x} \log \frac{I_{0}}{I} e$ levando em conta a definiçäo de densidade ótica ( 0.0.$):-0.0 .=\log \frac{I_{0}}{I}$ te remas $K=\frac{2,3}{x}$ O. D. C, considerando ( II -5 ), temos

$$
\frac{\Delta K}{K}=-\frac{\Delta I}{I} \frac{1}{2,3(0.0 .)}
$$

Por outro lado, consideremos um sistema ao qual se aplica um campo elé trico f. entäo o mesmo exibirá para cada comprimento de onda da luz um coeficlente de absorçäo $K(f)$ que depende do campo aplicado. Desenvolvendo em série o valor de $K(f)$ en torno de certo $K\left(f_{0}\right)$ teremos

$$
K(f)=K\left(f_{0}\right)+K \cdot\left(f_{0}\right) f+\frac{1}{2} K \cdot\left(f_{0}\right) f^{2}+\frac{1}{6} K \cdots\left(f_{0}\right) f^{3}+\cdots
$$

Sendo $f=\bar{f} \operatorname{sen} \omega t$ onde $\bar{f}$ é a amplitude do campo aplicado ac, obtere mos entäo, omfitindo os termos de ordem mais elevada: 


$$
\begin{aligned}
& K(f)=K\left(f_{0}\right)+K^{\prime}\left(f_{0}\right) \bar{f} \operatorname{sen} \omega t+\frac{1}{2} K^{\prime}\left(f_{0}\right) \bar{f}^{2} \operatorname{sen}^{2} \omega t \quad \therefore \\
& K(f)=K\left(f_{0}\right)+K\left(f_{0}\right) \bar{f} \operatorname{sen} \omega t+\frac{1}{4} K^{\prime}\left(f_{0}\right) \bar{f}^{2}(1-\cos 2 \omega t)
\end{aligned}
$$

No caso do centro $F$ que apresenta total inversāo de simetria esperamos ob ter $K(f)=K(-f)$, consequentemente $K^{\prime}(0)=0$. Considerando o caso. qua $K\left(f_{0}\right)=K(0)$ teremos

$$
\begin{aligned}
& K(f)=K(0)+\frac{1}{4} K^{\prime \prime}(0) f^{2}(1-\cos 2 \omega t) \text { ou sefa } \\
& \Delta K=K(f)-K(0)=\frac{1}{4} K^{\prime \prime}(0) f^{-2}(1-\cos 2 \omega t)
\end{aligned}
$$

Vemos assim que as variaçōes de absorçāo induzidas pelo campo íiétrtoo medirão um efalto com frequéncla dupla $(2 \omega)$ da frequência do campo.

\section{II.2. - TEORIA DO EFEITO STARK.}

Como o centro F possui inversão de simetria, os seus estados ، quànticos nāo possuem momento de dipolo. Entretanto, por ação do campo aplicado, é induzi do o aparecimento de um momento de dipolo do centro $F$ e é este fato que possib1 lita a existência de um efeito Stark de 2 : ordem do centro F.

A indução de um momento de dipolo $\overrightarrow{\Delta d}$, por açäo do campo elétrico aplicado, acarreta modificaçōes nos valores da energia de transição entre os esta dos excitados $\varepsilon$ o estado fundamental. Essas modificaçōes nos valores da energia de transição podem ser expressas por $\Delta E=\overrightarrow{\Delta \vec{g}} \cdot \vec{\varepsilon}$ onde $\vec{\varepsilon} \dot{\varepsilon}$ o campo elétrico local decorrente do campo externo aplicado $\vec{f}$.

Considerando a banda de ahsorção $K_{f}(E)$, sob a açäo do campo elétrico. on de E é a energia fotônica, banda essa que é devida è $N_{x}$ centros no estado $|x\rangle$ e $N_{\bar{x}}$ centros no estado $|\bar{x}\rangle$ los estados $|x\rangle$ e $|\bar{x}\rangle$ são aqueles em que os momentos de dipolo induzidos apresentam orientaçōes opostas), podemos considerar. $\because$ que $K_{f}(E)$ è o resultado da superposição de duas sub-bandas:

$$
K_{f}(E)=n_{x} K\left(E_{1}\right)+n_{x} K\left(E_{2}\right) \text { ande }
$$




$$
n_{x}=\frac{N_{x}}{N_{x}+N_{x}^{-}} \quad \& n_{x}^{-}=\frac{N_{x}}{N_{x}+N_{x}^{-}} \quad\left(n_{x}+n_{x}^{-}=1\right)
$$

Cada ume destas sub-bandas correspondem a estados excitados em que as anergias fotōnicas sofrem variaçōes de sinais conträrios, por ação do campo aplí cado, 1sto $\dot{e}, E_{1}=E+\Delta E$ e $E_{2}=E-\Delta E$.

Assim temos :

$K_{f}(E)=n_{x} K(E+\Delta \dot{E})+n_{x} K(E-\Delta E)$

Na ausència do campo aplicado temos :

$$
K(E)=n_{x} K(E)+n_{x} K(E)
$$

Consideranjo o pequeno tamanho de $\Delta E$ em relaçào a largura da banda, pode mos exprimir a igualdaje (II-7) numa série de potências de $E$, fazendo isto $\theta$ subtraindo (II-8) de (II-7), após despresar os termos de malor ordem, obtamos entāo, para $\Delta K(E)$, variação do coeficiente de absorção pela ação do campo aplicado

$$
\Delta K(E)=K_{f}(E)-K(E)=\left(n_{x}-n_{x}\right) K^{\prime}(E) \Delta E+\frac{1}{2}\left(n_{x}+n_{x}\right) K^{\prime}(E)(\Delta E)^{2}
$$

Como, estatisticamente, não existe motivo para que o nümero de centros $|x\rangle$ seja maior que o de centros $|\bar{x}\rangle$ resulta que teremos $n_{x}=n_{x}$, nestas condiçōes para o caso do centro $F$ o efeito de primeira ordam, ou seja o efeito Stark Innear, é cancelado, o observamos apenas a existéncia do efeito de 2 a ordem, pa ra luz polarizada paralelamente a direção do campo aplicado.

Como $n_{x}+n_{\bar{x}}=1$, a variação de absorção no efeito de 2 . ordem é expres sa pela igualdade

$$
\Delta K(E)=\frac{1}{2} K^{\prime \prime}(E)(\Delta E)^{2} \quad(\text { II - 9) }
$$

De acördo com esta última igualdade vemos que o efeito de 2 . ordem tem uma curva espectral do tipo da curva correspondente à da $2^{a}$. derivada da abanda de absorção.

Desde que se calcule $K^{\prime \prime}(E)$ a ültima igualdade oferece um meio de deter- 
minaça direta de ( $\triangle E)$.

Afin de determinar $\Delta E$ con a Igualdade acima, vamos levar em conta o farmato especif1eo de curva de absorcāo do centro $F$ que, multo aproximadamente, po demos considerar como sendo representada pela funçāo gaussiana

$$
K=k_{0} a^{-a}\left(E-E_{0}\right)^{2}
$$

ande $K_{0}$ - $E_{0}$ sào os valores do coeflciente de absorcào a da energia fotöntca. que correspondem do pico de benda de absorcào. A constante a está . rislacionede con a mala larguro da banda. w por

$$
-\frac{4 \ln 2}{w^{2}}
$$

Despresamos aqul o fato de que para uma representaça analit1ca ma1s per falta o parómetro a para o ramo de alta energla a o de baixa energla da curva. dsfere. porcentusimente, de algumas unidedes.

A mäxima variaça $\Delta K(E)$, no efeito de segunda ordem, ocarre no centro da bande ( pare $E=E_{0}$ ) e nestas cond1çōes, pelas Iguoldades anteriores temos

$$
\left[K^{\prime}(E)\right]_{E=E_{0}}=-\frac{\theta \ln 2}{w^{2}} k_{0}
$$

Colocando este resultado no segundo termo de ( II -9), para o pleo da absoredo temos

$$
\frac{\Delta K}{K}=-\frac{4 \ln 2}{w^{2}}(\Delta E)^{2}
$$

igualdade esta que permite calcular $\triangle E$ a partir dos resultados experimentala .

Como $\Delta E=\Delta \vec{d} \cdot \vec{E}$ a considerando que o centro $F$ é constituido por um alé tron capturado por uma vacancia negativa, entăo, se Z è um comprimento conve -

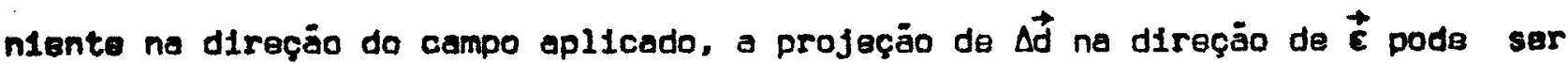
expressa por (eZ) onde e $\bar{e}$ a carga do eletron. Assim $\triangle E$ aZE - Substituztnda este valor en (II -10 ) teremos $\frac{\Delta K}{K}=-\frac{4 \ln 2}{W^{2}}(e Z \varepsilon)^{2}$. Considerando $w$ ex 
presso em eletron-volts teremos $e=-1$ e assim poderemos escrever:

$$
\begin{aligned}
& \frac{\Delta K}{K}=-4 \ln 2\left[\frac{\varepsilon}{U}\right]^{2} z^{2}, \text { ou seja } \\
& z^{2}=0.36 \frac{\Delta K}{k}\left[\frac{\omega}{\varepsilon}\right]^{2}
\end{aligned}
$$

II.3. - Q MÉTODO DOS MOMENTOS.

o cálculo teórico do tipo com que deve se apresentar a forma da linhe de absorçāo de um centro de cōr a o efaito de uma perturbação externa sobre a forme dessa linha é uma tarefa extramamente diflc1l. Entretanto, o efelto de per turbaçöss sobre as formas das linhas de ressonāncia magnética foram i: satudados por Van Vlek (9). Ele mostrou que apesar de ser multas vezes quase impossível o cálculo exato da forma da linha, os momentos da linha poderiam ser rigorosamen* te determinados a comparados com as resultados experimentais. Esse tipo de cálculos ficou conhecido cam o nome de "Métado dos Mamentos".

A aplicação do método dos momentos à forma da linha de absorçāo fol felto por Lax (10). Mais tarde. Henry Schnatterly e Slichter (2) desenvolveram um método mais simples a direto para o cálculo dos momentos, cujas linhas gerais sảo apresentadas abaixo. Se bem que o cālculo de um ou vārios momentos nāo permite prever a forma da linha, a variaçäo dos momentos por efelto de perturba cöes aplicadas podem ser preditos e comparados com a experiencia, podendo dal serem deduzidos valores de parâmetros da estrutura.

Sendo $E$ a energia do foton, define-se una função $f(E)$, chamada "fançào de forma" da linha de absorção, função esta mais fäcil de tratar i teoricenente que a função K(E) (coeficiente de absorção), por definição.

As funçōes $f(E)$ e $K(E)$, estão relacionadas pela igualdade $K(E)=C E f(E)$. sendo C uma constante.

Apōs a aplicaçāo de uma perturbação a funçāo de forma $f(E)$ modifica - se 
para $g(E)$.

Säo definidos os seguintes momentos:-

a) 0 momento de ordem zero, que denota "área", dado por:

$$
A=\int f(E) d E
$$

A integraçäo se estende ao intervalo de energla correspondente a uno banda determinada.

b) O momento de ordem 1. que denota "centro de gravidade". $\dot{8}$ definido co mo:

$\langle E\rangle=\bar{E}=A^{-1} \int E f(E) d E$

c) Todos os momentos de ordem suparfor à 1 säo definidos pela jexpresääo geral $(n>2):-$

$\left\langle E^{n}\right\rangle=A^{-1} \int(E-\bar{E})^{n} f(E) d E$ $(I I-14)$

O segundo momento $\left\langle E^{2}\right\rangle$ apresenta um interesse especial por ser ele uma medide do "espralamento" ou "alargamento" de bonda.

Um dos importantes resultados a que chegaram Henry a os outros, $\dot{8}$ que o momento de ordem zero ("área") permanece inalterado pela aplicaçào de ume per turbaçäo, ou seja

$$
A=\int f(E) d E=\int g(E) d E
$$

A variaçäo do momento de 1 . ordem á dada por

$$
<\Delta E>=\int E[g(E)-f(E)] d E
$$

As varleçöes dos momentos de ordem superior à primeira sāo dadas por

$$
<\Delta E^{n}>=\int(E-E)^{n}[g(E)-f(E)] d E
$$

Para o caso do efeito Stark, a perturbaçāo. $H_{p}$. usada nos cálculos a

$$
H_{p}=-B Z \varepsilon
$$

onde e é a carga do elétron, (ez) é o momento de d1polo Induzido por açào do campo aplicado e $\varepsilon \dot{\varepsilon}$ o campo elétrico local consequente ao campo elétrico exter no aplicado na direção $Z$. 
II.4. - PREVISOEES TEORICAS PELO "MÉTODO DOS MOMENTOS".

0 "Mētodo dos momentos", Idealisado para a análise do efeito de perturbeçōes no comportamento de um sistema fol entāo aplicado afím de realisar uma previsāo teórica sobre o efeito produzido pela perturbação de um campo elétrico externo na linha de absorçäo do centro F. Para fazer suas previsöes.Henry Schna tterly a Slichter supuseram que a açāo do campo elétrico tem por efeito mistu rar os estados $2 s$ e $2 p$, aproximadamente degenerados, dendo origem à um efa1to Stark de $2^{a}$. ordem.

A absorção ótica da banda $F$ dos halogenetos alcalinos, de acordo com os modelos quänticos imaginados para estudo do centro F, grouśm de uma transiçāo e Letrônica do estado fundamental is para o estado excitado $2 p$. Como na fisica atômica, a transiçāa ls $\rightarrow$ 2s nāo é permitida.

Henry Schnatterly e slichter calcularam as variaçöes teöricas nos momentos de ordem zero, ordem 1 e ordem 2 da banda $F$, que ocorrem devido à perturbaçāo representada pela ação de um campo elétrico.

Como fol indicado anteriormenta, o momento de ordem zero näo muda. Ver1flceram Igualmente que o momento de ordem 1 tambëm näo deve se alterar, Indican do Isto que a posição do centro de gravidade da curva de absorção não deve ser modificada por efeito da perturbação.

Para luz polarizada paralelamente a direçāo do campo elétrico aplicado ( d1reçāo Z) a variaçäo no momento de $2^{a}$ ordem deve ser

$$
\left\langle\Delta E_{z}^{2}\right\rangle=(\theta \varepsilon)^{2}\left|<2 p_{z}\right| z|2 s>|^{2}
$$

ande a é a carga do eletron, $\varepsilon$ é o campo elétrico local, $\left|2 \mathrm{p}_{z}\right\rangle \bar{e}$ o estado $2 \mathrm{p}_{z}$ e $|2 s\rangle$ à o estedo $2 s$.

As componentes em $x$ e en $y$ da variação do momento de segunde ordem $\left\langle\Delta E_{x}^{2}\right\rangle$ $\left\langle\Delta E_{y}^{2}\right\rangle$ se anulam, Indicando que não existe efeito Stark para luz polarisada perpendicularmente à direção do campo elétrico aplicado 


$$
\left\langle\Delta E_{x}^{2}\right\rangle=\left\langle\Delta E_{y}^{2}\right\rangle=0
$$

De acordo com as previsöes teóricas feitas, duas hipóteses poderian ocor rer:-

1.) A seperaçäo $\Delta$ entre os níveis dos estados $2 s$ e $2 p$ a menor que melo largura $W$ da banda $F$, caso em que os estados $2 s$ e $2 p$ seriam aproximadamente degenerados (oticamente nëo resolvidos).

2.) A separaçào $\Delta$ é maior que a meía largura da linhe da banda $F$ e entăo os estados $2 s$ e $2 p$ estarào resolvidos.

No primeiro caso a varłaçāo relativa do coeficlente de absorção é expres sa, teoricamente, por

$$
\frac{\Delta K}{K}=\frac{\left\langle\Delta E_{z}^{2}\right\rangle}{2\left\langle E^{2}\right\rangle}
$$

No segundo caso temos

$$
\frac{\Delta K}{K}=-\frac{\left\langle\Delta E_{z}^{2}\right\rangle}{\left(E_{2 p}-E_{2 s}\right)^{2}}
$$

o valor $\Delta$ determina não só a magnitude do efeito mas também a forma da curva de varlação $[g(E)-f(E)]$

A representação esquemätica dos orbitals não perturbados corrospondente oos estados $2 s$ e $2 p$ e perfeitamente simëtrica como se indica ne figura 2.

Ds niveis de energia correspondentes estào indicados esquematicamente na figura 4-a.

O especial significado do efeito Stark consiste em que a açăo do campo produz a mistura dos estados $2 s$ e $2 p$, Isto $\bar{e}$, a função de onda referente a cada um destes estados que eram $\phi_{1} B \phi_{2}$, passam a ser $\Psi_{1}$ e $\Psi_{2}$, representadas,cada uma, por uma mistura das funçães de onda primitivas $\psi_{1}, \psi_{2}$, 1sto é teremos

$$
\Psi_{1}=a \psi_{1}+b \psi_{2} \text { e } \Psi_{2}=a \psi_{2}+b \psi_{1}
$$

Nestas condiçōes o eletron tem probabilidade de estar nos dols estados.

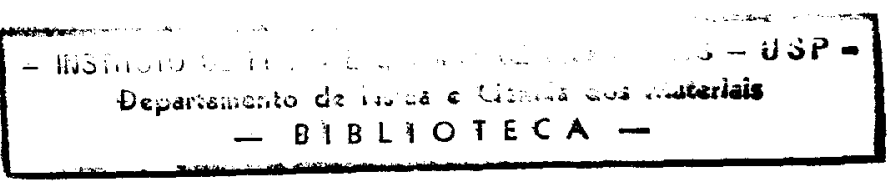


2s a $2 p$. ao mesmo tempo , disse resulta uma modificaçào das probabilidades de transiçào radiativa das estados, ben como das respectivas energias.

Em consequéncia da mistura dos estados $2 \mathrm{~s}$ e $2 \mathrm{p}_{z}$ torna-se permitido que . Iuz polartsada paralelamente a f possa excltar a transiçäo proibida is $\rightarrow 2 s$, expensas da transiçäo $1 s+2 p$.

Estas consideraçōes permitem compreender qual influencio do volor de $\Delta$.

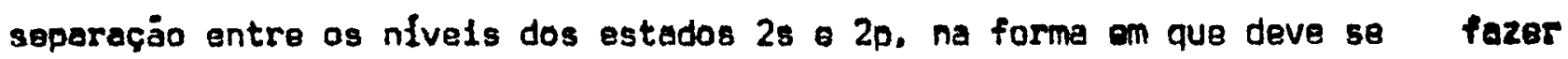
sentir o efelto Stark. Esta Influencia fica clara se levarmos em conta que, como mostra o "mëtodo dos momentos", as momentos de ordem zero ("ärea") a de ordem 1 ("centro de gravidade") nāo sào alterados por efelto da perturbaçăo. Nestas condiçōes, se $\Delta>W$ (half width), as duas bandas estäo bem resolvides a prevē-se, em consequêncla do surgimento da banda is $\rightarrow 2 s$ um decrescimo da bande is $\rightarrow 2 p$. Como o momento de ordem zero näo í alterado, entäo, o campo elätrico causa un aumento de área de banda $15 \rightarrow 2 s$ a um decráscimo igual para a área $13+2 p$. Além disso as duas bandas se deslocam am sentidos opostos para assegurar que o momento de primeira ordem näo şja altarado. Em virtude da grande separaça $\Delta$ entre as duas bandas, o aumento da benda $15+2 s$ às expensas da ban do 1 is $\rightarrow 2 p$. provoca modiftcaçōes pronunctadas na curva de absarção.

Se $\Delta$ é menor que $W$, ou seja. os estados $2 s$ a $2 p$ são aproximadamente dege nerados, o aumento da banda $1 \mathrm{~s}+2 p$ às expensas da banda $1 \mathrm{~s} \rightarrow 2 p$, näo provocará modificaçöes multo pronunciadas na curva de absorção, e o efaito se resumirá pro ticamente num alorgamento da banda $1 s \rightarrow 2 p$ ao mesmo tempo que há uma pequena di minuição na altura da pico afím de ser mantida a área da banda.

Além disso o método dos momentos permite prevar a existéncia de uma mistura entre estados $p$ de ordem superior com a estado 25. Como os estados $p$ de or dem superfor são responsáveis pela banda $K$, que, em geral se apresenta bem re solvida en relaçào à banda F, decorre daf, que deve existir certa compensaçāo 
entre as áreas das bandas $K$ e F: a érea da bande $K$ deve decrescer a da benda F deve crescer por un valor correspondente.

En resumo. o efeito Stark sobre o centro $F$ deve ter as seguintes proprie dedes, previstas de acordo com o mätodo dos momentas:

a) Para un dado comprimento de onde, existo uma dependénclo "quedrátstoa entre $\frac{\Delta K}{K}$ o campo elétrico apl1cedo.

b) O efelto ocorre somente para a luz plano polarisada paralelamente à direçäo do cempo elétrico aplicado.

c) O efelto se manifesta por um elargamento da banda $F$, com un decrése1mo de absorģáo no plco da banda.

d) Existe uma pequena compensacāo entre as äreas das bandas $K$ e $F$.

Alèm das pravisōes teóricas aeima, proporclonadas pelo mmétodo dos moman tos". segundo G. Chiarott1 (3). usando as aproximaçōes teöricas geralmente acel tes para o centro F, com as quals sảo obtidas para o mesmo funçōes de onda do tipo das do ätomo de hidrogēnio, entāo. com auxflio dessas funçōes de onda rala tIvos sos estados $2 s$ a $2 p$, pode ser avaliado o elemento de matriz $\left\langle 2 p_{z}|2| 2 s\right\rangle$. De acordo com Chiarott1 (3), obtem-se para esse elemento de matriz, no caso do KCl. o valor $3 a_{0}$, onde $a_{0}$ e o "primelro ralo de Bohr" $\left(a_{0}=0,529 \times 10^{-8} \mathrm{~cm}\right)$.

\section{I1.5. - RESULTADOS EXPERIMENTAIS DBTIDOS POR CHIAROTTI E OUTROS PARA O CENTRO F} EM KCL.

Em 1966, Chiarott1 e outros, (3), mediram o efelto Stark sobre centro $F$ en KC1 a verificeram que as previsōes do método dos momentos apresentavam uma concordancia excelents com os resultados experimentals obtidos.

A figura 5.a mostra o resultado obtido por Chiarotti para a variaçäo do coeficlente de absorção $\Delta K=-\frac{1}{x} \frac{\Delta I}{I}$, para um cristal de $K C I$ aditivamente colorido, en funçà da snergia dos fotons. As medidas foram feltas com luz näo 
polarisada, tendo sido verificado que nenhum efelto era obtido com luz polarisa da perpendicularmente à direçāo do campo aplicado. A figura 5.b mostra os resul tados obtidos pare a dependéncia $\frac{\Delta K}{K}$. no mäximo da banda $F$. com o valor do quadrado do campo eplicado.

Para os plcos dos bendas $F$ a $K$. segundo (3), foram obtidas os suguintos rasultados: $\frac{\Delta K_{F}}{K_{F}}=-2.8 \times 10^{-5}$ e $\frac{\Delta K_{K}}{K_{K}}=-10.9 \times 10^{-5}$.

De acordo com os resultados obtidos por Chiarott1, poude-se conclulr que, para luz polerisada paralelamente à direçào do campo externo aplicado, hä um pe queno aumento do momento de 2 . ordem do banda $F$. com quase nenhuma varleçöo da área ou momento de 1 : ordem, a também, que a curve de $\Delta x$ tem um formato do t1Do da curva representativa da derivada segunda da funçäo $K(E)$, denotando sstas

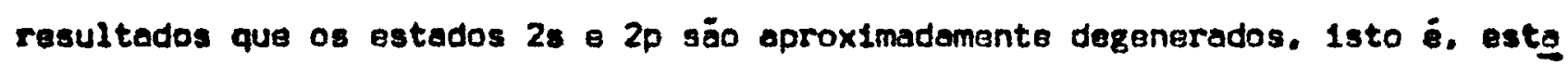
mos no caso en que $\Delta<W$. Nestas condiçöes a expressäo de $\frac{\Delta R}{K}$ para o pleo do banda $F$ deve ser dada por ( II -16) a não por ( II - 17), 1sto B. daveramas ter $\frac{\Delta K}{K}=-\frac{\left\langle\Delta E_{z}^{2}\right\rangle}{\left.2<E^{2}\right\rangle}$.

De acordo com Chiarotti, a evaliaço do elemento de matriz a partir dos resultados experimentals por ele obtidos permite chegar a valor aproximado 1gual a $4 a_{0}$, onde $a_{0}$ é ralo de Bohr.

Deve ser destecado que na avaliacáo do elemento de metriz pelo use da färmula ( II -11) ou ( II - 21 ) o resultado experimental obtido para $\frac{\Delta K}{K}$ deve aer multiplicado por 2 afim de ser levado en conta o fato de que, nas medidas $E$ fetuadas fol usada luz näo polarisada, o que duplica o valor correto de I. Nestas cond1cōes os valores de $\frac{\Delta K}{K}$ a serem utilisados nos cälculos deverāo ser:

$$
\frac{\Delta K_{F}}{K_{F}}=-5.6 \times 10^{-5} \cdot \frac{\Delta K_{K}}{K_{K}}=-2.18 \times 10^{-4}
$$


II.6. - FORMA DE COMPARACÃO ENTRE AS PREVISOES TEÓRICAS E OS RESULTADOS EXPERI-

\section{MENTAIS.}

Afim de testar os modelos de que se serve a teoria, comparamos as prevI sōes teöricas com os resultados experimentais.

No nosso caso, para esse fim, podemos comparar o valor teórico obtido para o elemento de matriz $<2 p_{z}|z| 2 s>$ com o valor experimental do mesmo obtido por melo do uso do "método dos momentos".

AfIm de calcular esse elemento de matriz a part1r dos resultados experi mentais procedemos do seguinte modo:

Consideramos que a curva de absorçēo do centro $F \bar{e}$, aproximadamente, uma goussiana de equação

$$
K(E)=K(\bar{E}) e^{-\left[\frac{2 \sqrt{\ln 2}(E-\bar{E})}{w^{2}}\right]}
$$

onda is a a mela largura da banda ( half width ) e $K(\bar{E}$ ) é o valor máximo do coeficiente de absorçäo.

Os momentos sarão dados por:

Momento de ordem zero: $A=\frac{\sqrt{\pi} K(E) W}{2 \sqrt{\ln 2}}$

Momento de primeira ordem: $\langle E\rangle=\bar{E}$

Momento de segunda ordem : $\left\langle E^{2}\right\rangle=\frac{w^{2}}{B \ln 2}=0,18 W^{2}$

Considerando que a expressão de $\frac{\Delta K}{K}$ deve ser dada pels equaçāo (II-16). 1sto $\dot{e}$, que $\frac{\Delta K}{K}=-\frac{\left\langle\Delta E_{Z}^{2}\right\rangle}{2\left\langle E^{2}\right\rangle}$. Subst1tuindo, na ültima 1gueldada, o valor de $\left\langle E^{2}\right\rangle$ pela sua expressão dada em (II -20) a o valor de $\left\langle E_{Z}^{2}\right\rangle$ pela sua expressão dada en (II -15) teremos

$$
\frac{\Delta K}{K}=-\frac{(\mathrm{e} \varepsilon)^{2}\left|\left\langle 2 p_{z}|z| 2 s\right\rangle\right|^{2}}{0,36 W^{2}}
$$


deve ser tomado como e $=-1$, deste modo a ültima igualdade poderá ser escrita :

$$
1<2 p_{z}|z| 2 s>\left.\right|^{2}=-0,36 \frac{\Delta K}{K}\left[\frac{w}{\varepsilon}\right]^{2}
$$

expressão esta idēntica ao valor $z^{2}$ obtido anteriormente em (II -11).

Como Wé conhecido experimentalmente, podemos obter o valor do elemento de matriz desde que possamos avaliar o campo eletrónico local $\varepsilon$. 0 valor de $\varepsilon \cdot \dot{e}$ desconhecido, mas, uma alternativa seria exprimir $\varepsilon$ pelo valor de " campo de Lorentz" dado por $\varepsilon_{L}=\frac{k_{S}+2}{3} f$, onde $k_{s}$ é a constante dielétrica estática do cristal e f è o valor do campo externo aplicado ( "peak"), entretanto isso exI girla despresar a interaçäo entre a carga do centro $F$ e as dos seus vizinhos. De qualquer modo, é sempre razoével supor que o campo local seja sempre que o campo elétrico aplicado. embora não tão grande como o " campo de Lorentz" $E_{L}$ 
CAPITULO III.

\section{PARTEEXPERIMENTAL}

III.1. - CONSIDERACÕES BÁSICAS SOBRE A TÉCNICA EXPERIMENTAL.

Camo vimos no tópico II.1., a variação $\Delta K$ do coeficiente de absorção é expressa por $\Delta K=-\frac{1}{x} \frac{\Delta I}{I}$. Assim, as variações $\Delta K$, produzidas por ação do campo elétríco podem ser determinadas pela medida das correspondentes variações $\Delta T$ da intensidade I da luz transmitida, como função da energia do fóton $E$.

$\epsilon$ sabido que as variaçōes $\frac{\Delta K}{K}$ produzidas pela ação dos campos elétricos, são, no caso, da ordem de $10^{-5}$ para campos de cerca de $50 \mathrm{kV} / \mathrm{cm}$ (peak). Is to implica em que devemos determinar uma pequeninissima variação do topo de um forte sinal dc causado pela luz transmitida.

Considerando a detecçäo por uma fotomultiplicadora, sabemos que o sinal eletro-ótico $\Delta I$, para um dado campo elétrico aplicado, aumenta em proporção direta com a intensidade da luz transmitida I, ao passo que a principal ruido,pro duzido na fotomultiplicadora ("shot noise") é proporcional à raiz quadrada de I, 
assim uma intensidade de luz täo alta quanto possível seria favorável para obter uma melhor relaçäo sinal/ruido. Mesmo assim, devido ao pequeniníssimo valor da fraçäo $\frac{\Delta K}{K}$, a medida do efeito Stark exige, para sua determinação, que se tire partido da periodicidade e exata diferença de fase sntre o sinal causado por $\Delta I$ no detector a o campo aplicado, em comparaçäo com o ruido, totalmente ao acaso. Isto exige o uso de um amplificador altamente sensivel à frequéncio a fa se do sinal que se quer determinar. Tal tipo de amplificador é conhecido como "lock-1n".

Inicialmente ut1izamos o "lock-in" modeln PAR-122 e, posteriormente, un modelo bem mais aperfeiçoado, o PAR-128.

III.2. - VALORES OTIMOS PARA AS DIMENSÕES DA AMOSTRA E CONCENTRAČAO DE :CENTRDS DE COR.

Sendo $\Delta K=-\frac{1}{x} \frac{\Delta I}{I}$ e $I=I_{0} \theta^{-K x} \quad \therefore \Delta I=-x \Delta K I_{0} \theta^{-K x}$ afim de procu rar o melhor comprimento do caminho ático $x$ através da amostro afim de que um méximo no valor do sinal $\Delta I$ devemos ter $\frac{d \Delta I}{d x}=0$ ou seja:

$-(\Delta K) I_{0} e^{-K x}+x K(\Delta K) I_{0} e^{-K x}=0$

Entäo temos $x K=1$ como condiçāo ótima para obtermos o valor máximo do sinal.

Por outro lado, como $x K=2.30$. 0. resulta que, com a extensä́o do cominho ót1co utilisado, a concentraçāo de centros de cor deve ser aquela que acarreta ume densidade ótica $0.0 .=\frac{1}{2,3}$ ou seja 0.44 . qualquer que seja a exten são do caminho ót1co utilisado. Assim, para caminhos óticos de maior extensáo a concentracajo dos centros de cor deve ser proporcionalmente menor e vice-versa.

III.3. - APARELHAGEM PARA EFEITO STARK. 
A aparelhagem ut1lisada é semelhante à que se usa em muitos sistemas ele tro- óticos de medida.

A flgura 6 mostra un diagrama em bloco da aperelhagem utilisada. Näo se utilisou luz polarisada. A fonte de luz do monocromador BauschLomp fol alimentada por uma batería de 6V afim do eliminar a modulação da luz pela tensäo de 60 clclos. As aberturas de entrada e saida do monocromador foram escolhidas de modo que o mesmo apresentasse a melhor resoluçäo poss Ivel (3mu) . Uma lente focalisava a luz sobre a amostra no criostato, enquanto o cristal estava à temperatura do nitrogênio liquido $\left(78^{\circ} \mathrm{K}\right)$.

A luz que atravessava o cristal era focalisada, com auxilio de outra len te. sobre a roda dentada do "chopper" e sobre a face sensivel da fotomultiplico dara. D "chopper" tinha a funçāo de modular o feixe luminaso quando se preten dia determinar I. Para isso ele era munido de uma lanterna alimentada à bateria cuja luz incidia sobre ums LDR ( Ilght dependent resistor) que fornecia o sinal de referencia ao "lock-In". proventente da modulaçäo do "chopper".

A luz que atravessava o cristal era detectada por uma fotomultiplicadora EMI 9558-DA.

A parte ac do sinal fornecido pela fotomultiplicadora era levada ao lockIn ao mesmo tempo que a corrente da foto podia ser monitorada com auxilio de um medidor Phllips "DC multifunction voltmeter DM 2436" com sensiblidade desde $10 \mathrm{pA}$.

A modulaçăo da variaçäo de absorção do cristal, devida ao efeito stark. a fim de que essa variaçào de absorção pudesse ser medida com a técnica do "lockIn". era realisada à custa da aplicaçào de um campo elétrico externo ac sobre o cristal, transversalmente à direçäo de propagaçäo do feixe luminoso. Esse campo externo era produzido pela fonte de al ta tensão, que era um ampliador de tensão alimentado por um oscilador que trabalhava em $100 \mathrm{~Hz}$ ou $340 \mathrm{~Hz}$. Tanto o ascila- 
dor como a fonte de alta tensāo produziam ume tensäo ac senoldal. A tensáo da fonte era medida a monitorade com auxillo de um osciloscōplo " Tectronix" mun1do de ponta redutora de tensäo na proporçäo de 1000 paro 1.

0 osclladar tambèm fornecla o sinal de referéncla ao "lock-in". necessàr10 à medida da variaçäo $\Delta I$ da intensidade da luz emergente do cristal, variaçào esta detectada pela fotomultiplicadora.

Evidentemente, quando se media $\Delta I$ o "chopper" năo estava em operaçäo, mas a sua roda dentada estava colocada de tal modo que a luz passava entre dols de seus dentes.A densidade ötica das amostras ( 0.0 . ) era medida à temperatura ambiente com auxilio de um espectrofotōmetro Cary 17. 0 "lock-1n" ut111sado fol - PAR - 128, que permitia uma sincronisaçāo automática entre a referência e o sinal, dispunha de recursos, para reduçäo de ruldo, beseados em limitação da falxa de frequēncla en que era permitida detecçāo e adequada organiseçäo da 11gaçōo à terro. A sensibilidade do "lock-in" la até centésimo de microvolt e dis punhe de salda especlal que era ligado à um registrador $(y, t)$.

\section{III.4. - PREPARACÃO DAS AMOSTRAS.}

As amostras de $\mathrm{KCl}$ e $\mathrm{KBr}$ puros foram crescidas no vácuo pelo processo de Kyropoulos.

As amostras de KBr foram coloridas pelo processo de coloraçäo aditiva de modo a apresentarem no final uma concentraçāo de centros F prōxima do valor 1deal requerido.

As amostras de KCL foram coloridas por meio da irradlaçāo com raios $x$ na temperatura ambiente. A irradiaçāo era feita atravēs de uma placa de proteçāo de aluminio, com cerca de $2 \mathrm{~mm}$ de espessura ofim de que ficasse eliminada a açäo da parte de balxa energia da irradiaçāo pois, apesar desta ser mais eficlente en colorir o cristal, como ela é facilmente absorvida produz uma coloraçào năo 
uniforme através da espessura da amostra. Afim de controlar este resultado e também para determinar as condiçōes de irradiaçăo convineientes para produzir o grau de coloração ideal requerido, värias amostras eram irradiadas en condiçöes gradativamente diferentes a apōs serem clivadas, subdividindo-as aproximadamente pelo meio, era medido o coeficlente de absorçăo das duas partes com o espectrofotōmetro Cary 17 e também era medida a espessura de cada uma das partes.Por esse modo foi possivel determinar as condiçōes que produzlam coloraçăo uniforme e nograu desejado.

Como è mostrado na figura 6 , os cristais de $\mathrm{KCl}$ foram coloridos de modo que a absorção de luz se desse numa faixa de apenas cerca de $2,5 \mathrm{~mm}$ de largura. Isto fai abtido com o uso de uma blindagem de chumbo que apresentava uma "Janela" com a largura indicada, de modo que apenas a parte do cristal de frente para a janela era irradiada com os raios $x$ e assim colorida.

Depols de coloridos os cristals eram manipulados apenas no escuro au com fraca lluminação de luz vermelha.

A espessura minima das amostras (dimensão entre os eletrodos) era de $1 \mathrm{~mm}$, valor este que representava um compromisso entre o "mais fino". conveniente por acarretar um campo elétrico mais intenso, e o "mals grosso", convenlente para minimizar as possibilidades de reflexão interna da luz nas faces da amos tra antes de emergir da mesma.

III.5. - IMPLICAÇÓES DA TEECNICA UTILISADA NOS VALORES DAS MEDIDAS.

De conformidade com o que já fol exposto, afim de medir a variaçào $\Delta K$ do coeflciente de absorção produzida pela açāo do campo elétrico, temos que determinar somente a relação $\frac{\Delta I}{I}$ entre a variaçäo de intensidade $\Delta I$ da luz transmi tida e a intensidade I da mesma.

Podemos considerar que essa relaçāo é a mesma que entre os sinais elétri 
cos gerados na fotomultiplicadora por $\Delta I$ \& $I$.

Para medir estes sinais, com a técnica do "lock-in", eles precisam ser modulados e, como vimos o sinal $\Delta I$ é modulado pelo uso de um campo elétrico ac, sinusoidal, em lugar de campo constante, ao passo que, para a medida de I a modulaçäo do feixe é feita com auxilio do "chopper", o que produz uma onda quadra da simëtrica.

Devemos ter em mente porém, que para um determinado sinal . lançado no "lock-1n". somente a componente de Fourrier para a qual o "lock-in" está sintonisado torna-se ampliada. Isto exige fatores de correção diferentes para as diferentes formas de sinais periódicos afim de que se possam determinar valores corretos de pico correspondentes às lelturas de valores fornecidas pelo "lock$1 n^{\prime \prime}$

\section{a) Para I:}

O desenvolvimento em série de fourrier da onda simétrica quadrada nos dá $y=\frac{2 a}{\pi}\left(\operatorname{sen} \omega t+\operatorname{sen} \frac{3 \omega t}{3}+\ldots\right)$

Como somente a componente fundamental é ampliada deveremos corrigir a. leitura com o fator $\frac{\pi}{2}$ para obter o valor de pico "a" ( em nosso caso I ).

b) Para $\Delta I$ :

Neste caso, se o efeito é de $l^{a}$. ordem, teremos $\Delta I=\bar{f} \operatorname{sen} \omega t$ e nenhuma correção é necessäría.

Se o efeito é de $2^{a}$. ordem temos $\Delta I \alpha \bar{f}^{2} \operatorname{sen}^{2} \omega t$.

Desenvolvendo $\operatorname{sen}^{2}$ wt temos:

$$
y=\operatorname{sen}^{2} \omega t=\frac{1}{2}-\frac{1}{2} \cos 2 \omega t+\cos 4 \omega t \ldots
$$

Assim afim de obter o pico do valor no efeito de $2^{a}$. ordem devemos multiplicar as leituras do "lock-in" por 2.

Em resumo as relaçōes $\frac{\Delta I}{I}$ devem ser corrigidas da seguinte forma: Para os efeitos de 1 . ordem: 


$$
\frac{\Delta I}{I}=\left[\frac{\Delta I}{I}\right]_{\text {lock-in }} \times 0,637
$$

Para os efeitos de 2 . ordem:

$$
\frac{\Delta I}{I}=\left[\frac{\Delta I}{I}\right]_{\text {lock-in }} \times 1.27
$$

Convém destacar que o fato de gus as madidas do "lock-in axprimiram lores médios quadráticos em lugar dos valores de plco da componente de Faurier que é sintonisada pelo aparelho não precisa ser levado em conta, pols, no nosso caso as correçōes $\left(\sqrt{2}\right.$ ) são canceladas na razão $\frac{\Delta I}{I}$. Desde que $I$, ou me Ihor, o sinal correspondente a I é conservado constante durante todas as medi das, a correção acima é feita uma única vez. Para manter I constante, isto é,pa ra obter uma leitura constante no medidor do sinal de da fotomultiplicadora (ví de esquema), independentemente das mudanças do feixe luminoso, das caracteristi cas da fotomultiplicadora ou mesmo da variação da densidade ótica, da amostra , poderemos ajustar seja a intensidade da luz incidente $I_{0}$ ou então a tensão de alimentação da fotomultiplicadora, que produz efeito equivalente. Durante os nos sos trabalhos optamos por esta última forma de procedimento, sem dúvida mais cô moda.

Pelo fato do "lock-in" ser também sensível à diferença de fase entre os sinais recebidos, 1sto é, o que se pretende detectar e o sinal de referēncia, en tão, o sinal de saida do "lock-in" é proporcional ao cosseno do ângulo $\delta$, que exprime essa diferença de fase.

Desta forma, num determinado arranjo experimental, o "lock-in parmite que seja feito um ajuste da fase dos sinais recebidos de forma a corrslacianar a polaridade do sinal de saida com aquela do sinal $\Delta I$, ao mesmo tempo que permI te maximizar a intensidade desse mesmo sinal de saida. 
verificar a calibraçāo de sitemas de medida do tipo que estamos considerando, as sim como para determinar a fase conveniente que dá o sinal algébrico correto do sinal de saida.

Quando se usa luz näo polarisada o rssultado experimental obtido para $\frac{\Lambda K}{K}$ deve ser multiplicado por 2, afim de ser levado em conta o fato de que o uso de luz não polarisada duplica o valor correto de I.

III.6. - O CRIOSTATO, MONTAGEM DA AMOSTRA E DETALHES DE OPERAÇÃO.

o criostato, construido nas oficinas do Departamento de Física, possui acesso com isolação adequada que permitia levar um dos polos da tensão exterlor para ser aplicada num dos eletrodos..em contato com a amostra. O outro polo da tensäo aplicada era a próprla carcassa do crisostato, à qual estava solidário o outro eletrodo.

Além disso o crisostato também possul o acesso apropriado para ligaçäo ao termo par cobre-constantan soldado ao eletrodo solidário com a carcassa do criostato.

0 portador da amostra, figura 6, era constituido pelos próprios eletro dos, e a amostra se mantinha no lugar por efeito de uma leve pressāo produzida por molas acionadas com parafusos de teflon e, respectivas porcas, colocados nos eletrodos. As molas eram bastante fracas, afim de evitar maiores pressöes sobre a amostra, que seriam capazes de criar diferenças de simetria no centro F sufi cientes para acarretarem variação de absorção do mesmo por esse efeito.

0 uso de finas camadas de indto, aderidas aos eletrodos, sāo importantes nāo só para o bom contato térmico da amostra com o dedo frio, mas também para ajudar a resolver o problema de "luz errante" ("stray light") que afeta o fun cionamento correto da fotomultiplicadora. As finas camadas de indio evitam a transmissäo espuria de luz entre as superfícies laterais do cristal 8 as super- 
ficies dos eletrodos em contato com elas.

Todas as arestas dos eletrodos foram cuidadosamente arredondadas e pol1das, afim de evitar sinais errôneos consequentes de pequenas descargas

nesses locais.

D problema da "stray 11ght" foi um dos que mais trabalho deram para ser controlado e não afetar a fotomultiplicadora. Afinal, o problema ficou resolvido do seguinte modo:

Dentro da cāmara escura na qual se propagava o feixe, construida com armação de madeira e placas de duratex, com as juntas vedadas por fita isolante preta de boa qualidade, providenciou-se a colocação de diafragmas confecciona dos com papel cartão, tomando toda a secção transversal da câmara escura : um diafragma munido com pequena abertura, suficiente para a passagem do feixe, foi colocado junto a janela de entrada da luz no criostato. Outro diafragma sameIhante foi colocado junto a entrada do feixe na face sensivel da fotomultiplica dora.

Um terceiro diafragma, feito com fina folha metālica, munido de pequeorifício, fol colocado preso ao dedo frio dentro do "copo" que fazia o "shield" térmico da amostra no criostato, figura 8. Este pequeno diafragma ficava numa posição do caminho ático interceptando a luz após a mesma ter atravessado a amostra.

No criostato era feito um vácuo melhor que $10^{-5} \mathrm{~mm}$ de mercúrio, após 0 que a amostra era resfriada até a temperatura do nitrogēnio líquido $\left(78^{\circ} \mathrm{K}\right)$. Afin de evitar a destruição dos centros F por ação da luz ("bleaching") a amostra somente era iluminada quando na temperatura do nitrogênio líquido.

Afim de evitar possibilidade de descargas internas, o campo era aplicado apenas quando o vácuo correspondia a $10^{-5} \mathrm{~mm}$ de mercúrio ou melhor a também a amostra em temperatura do nitrogênio líquido. A aplicação do campo deve ser gra- 
dual, afim de minimizar as possibilidades de descargas. Um procedimento que pode ser seguido é o seguinte: durante a aplicação iniclal da tensão, a mesma deve crescer em pequenos acréscimos, mentidos num perfodo de 5 minutos antes do acréscimo seguinte, afim de prevenir descargas na superfície do cristal. A foto multiplicadora, controlada pela medida do seu sinal dc, pode ser usada para monitorar estas descargas, desde que o monocromador esteja desligado.

Depois que se atingiu pela primeira vez uma tensão suficientemente eleve da a já não mais se produzem descargas, então, numa nova ocasião, a aplicação süblta da tensão total não causará novas descargas, desde que a tensão aplicada näo exceda o máximo alcançado anteriormente através de pequenos acréscimos.

\section{III.7. - RUIDOS.}

Devido à fraca intensidade do sinal a ser detectado que, como já indicamos, é uma variação que representa uma fraçäo da ordem de $10^{-5}$ no topo de um forte sinal dc, 1sto faz com que o problema dos ruidos na deteçäo se torne um dos mais importantes problemas que afetam o sistema de medida.

Após uma análise da questāo, podemos tentar classificar os ruidos que podem afetar o sistema, do seguinte modo, de acordo com suas fontes:

$\left.1{ }^{\circ}\right)$ ruidos provenientes da excessiva corrente de escuro da "fotomultipli cadora";

$\left.2^{9}\right)$ vibraçōes da fotomultiplicadora;

$\left.3^{\circ}\right)$ ruidos provenientes do próprio funcionamento da fotomultiplicadora (" shot noise "),

$\left.4^{9}\right)$ ruidos provenientes do funcionamento do prōprio sistema de medição por efeito de ação de harmônicos do sinal, tanto de ordem superior como de ordem inferior.

As providénclas adotadas para eliminação destes ruidos foram as seguin - 
$\left.1^{9}\right)$ Uso de uma càmara escura suficientemente vedada de tal forma que. no respectivo teste, o valor de corrente de ascuro de foto näo excedesse o recomendado pelo fabricante.

$\left.2^{9}\right)$ Uso de uma tensäo de alimentaçāo da foto, obtida na própria experièn cla, na qual o nivel de ruidos acusados no registrador caisse para um mínimo aceitável em face da sensibilidade da escala adotada para operar o "lock - in".

$\left.3^{\circ}\right)$ Além da providéncia anterior, o combate dos ruidos provenientes do funcionamento da foto ("shot noise") e os provenientes do funciona mento do sistema foram eficlentemente combatidos com o uso de um "lock-1n" de maiores recursos, o PAR-128, em subst1tulção ao que estava sendo usado anteriormente, o PAR-122. Além de permitir a eliminação de ruidos, por meio da possibilidade da limitação do range de frequèncias de sinals capazes de sensiblilsar de algum modo o apareIho, o PAR-128 permitia uma eliminaçäo de ruidos por açāo de harmōni cos, a custa da flexibilidade oferecide pelo mesmo de regular o "tem po de resposta" do aparelho ("time constant"), permitindo sem maio res complicações, adotar tempos de resposta até de 100 segundos, que foi largamente utilisado com muito sucesso. Evidnetemente com um tal tempo de resposta as medidas só poderiam ser feitas com auxilio de um registrador conectado à saida do "lock-in", e, a obtençāo de um registro consistente exigia que cada msdida tivesse a duraçäo de cer ca de 10 a 15 minutos de registro contínuo.

Além dos recursos indicados, um esquema de ligação à terra sugerido no

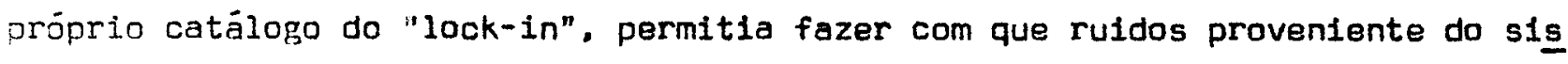
tema de ligação à terra ficassem reduzidos a um mínimo. 
CAPITULO IV. RESULTADOS, CONCLUSOESE SU-

\section{GESTOES.}

IV.1. - RESULTADOS OBTIOOS.

Nas flguras 9 e 10 säo mostradas as curvas de absorção obtidas para as a mostras de $\mathrm{KCl}$ e $\mathrm{KBr}$ utilisadas ( 0.0 . versus comprimento de onda ) com auxil1o do espectrofotōmetro " Cary - $17 "$ "

Nas figuras 11 e 12 apresentamos a reprodução de trechos de registro dos sinais obtidos para KCl e KBr, no efeito Stark.

Nas figuras 13 e 14 aparecem as curvas construidas com os dados abtidos, para $K C l$ e $K B r$, exprimindo a forma de variação de $\triangle K$ em função da energia dos fotons.

Na figura 15, vemos, para o KCl e KBr, a forma de dependéncia de $\frac{\Delta K}{K}$. - quadrado da intensidade do campo elétrico aplicado, para o mäximo de absorção da banda $F$.

Apresentamos em seguida o cálculo do valor de $\frac{\Delta K}{K}$, para temperatura do nitrogénio líquido e na energia fotônica correspondente ao pico da banda $F$, ten to para o KCl como para o $\mathrm{KBr}$.

18) Para o KCl.

Valor de $I=58 \mathrm{mV}$

Valor de $\Delta I=2,4 \mu \mathrm{V}$

Comprimento do caminho ótico na amostra $x=2,5 \mathrm{~mm}$

Espessura da amostra $\bar{x}=1,01 \mathrm{~mm}$

Campo aplicado $=7000 \mathrm{~V}$ pico à pico, ou seja, $3500 \mathrm{~V}$ "peak"

Curva de absorção levantada na temperatura ambiente:

(half width) $\rightarrow \mathrm{W}=0,31 \mathrm{eV}$

0.D. $=0,25$ (pico de absorção) 
a) Valor de $K$ na temperatura ambiente para o pico de absorção:

$$
K=\frac{1}{x} 2,3[0.0 .]=\frac{1}{0,101} 2,3 \times 0,25 \therefore K=5,7 \mathrm{~cm}^{-1}
$$

b) Valor de $K$ na temperatura do nitrogênio liquido ( $K_{T N L}$ ) :

A ärsa sob a curva de absorção independe da temperatura, consequente mente:

$$
W \times K=W_{T N L} \times K_{T N L}
$$

A variação de $W$ com a temperatura é dada no gräfico da figura 3-5,pg.55, do livro de Schulman (6), gräfico este reproduzido na figura 16, embora näo exista nessa figura a curva correspondente ao $\mathrm{KCl}$, como temos um ponto dessa cur va ( $W=0,31 \mathrm{eV}$ na temperatura ambiente), podemos, com auxilio desse ponto, in tercalar no gráfico a curva do $\mathrm{KCl}$, que deve acompantar o formato das demais. Traçada essa curva, podemos obter para o $\mathrm{KCl}$ que $W_{T N L}=0,18 \mathrm{eV}$. Assim teremos, de (1): $0,31 \times 5,7=0,18 \times K_{T N L} \therefore K_{T N L}=9,82 \mathrm{~cm}^{-1}$

c) Valor de $\Delta K$ normalisado para o campo de $4,5 \mathrm{kV} / \mathrm{cm}$

Afim de poder comparar o valor de $\frac{\Delta K}{K}$ com o valor obtido por Chiarotti. devemos calcular $\Delta K$ normalizado para o campo de $4,5 \mathrm{kV} / \mathrm{cm}$ ("peak"), valor este usado por Chiarotti. Essa normalisação é felta levando-se em conta que $\Delta K$ varia quadraticamente com o valor do campo.

o valor normalisado de $\Delta K$ será:

$\Delta K_{T N L}=\frac{1}{x} \frac{\Delta I}{I}\left(\frac{4,5}{\frac{3,5}{1,01}}\right)^{2}=\frac{1}{0,25} \frac{2,4}{58 \times 10^{2}}\left(\frac{4,5}{\frac{3,5}{1,01}}\right)^{2} \therefore$ $\Delta K_{T N L}=2,88 \times 10^{-4} \mathrm{~cm}^{-1}$

d) Valor da $\frac{\Delta K}{K}$, no pico de absorção, na temperatura do nitrogénio 1Iquido:

$\frac{\Delta K_{\mathrm{TNL}}}{\mathrm{K}_{\mathrm{TNL}}}=\left.\frac{2,88 \times 10^{-4}}{9,82} \therefore \frac{\Delta K}{\mathrm{~K}}\right|_{\mathrm{TNL}}=2,93 \times 10^{-5}$ 
0 valor obtido é praticamente colncidente com o obtido por Chiarotti que fo1: $\left(\frac{\Delta K}{K}\right)_{T N L}=2.8 \times 10^{-5}$

\section{9) Cálculo para o KBr.}

Valor de $I=362 \mathrm{mV}$

$$
\begin{aligned}
\Delta I & =3,0 \mu \mathrm{V} \\
x & =5 \mathrm{~mm} \\
\bar{x} & =2,2 \mathrm{~mm}
\end{aligned}
$$

Campo oplicado $=8200 \mathrm{~V}$ pico a plco

Curva de absorção da amostra: $0.0 .=0,2$

$$
W=0,36 \mathrm{eV}
$$

Valor obtido na figura $12 w_{T N L}=0,222 \mathrm{eV}$

a) Valor de $K$ na temperatura ambiente: $K=\frac{1}{0,22} 2,3 \times 0.2 . \cdot k=2.09 \mathrm{~cm}^{-1}$

b) Valor de $K$ na temperatura do nitrogênio líquido:

$$
2,09 \times 0,36=K_{T N L} \times 0,222 \therefore K_{T N L}=3,39 \mathrm{~cm}^{-1}
$$

c) Valor de $\Delta K$ normalisado para campo de $45 \mathrm{kV} / \mathrm{cm}$ :

$$
\Delta K=\frac{1}{0.5} \frac{3.0}{362 \times 10^{3}}\left(\frac{4.5}{\frac{4.1}{2.2}}\right)^{2} \because \Delta K=9.67 \times 10^{-5} \mathrm{~cm}^{-1}
$$

d) Cálculo de $\left(\frac{\Delta K}{K}\right)_{T N L}$

$$
\left(\frac{\Delta K}{K}\right)_{T N L}=\frac{9.67}{3,39} \times 10^{-5} \because\left(\frac{\Delta K}{K}\right)_{T N L}=2,85 \times 10^{-5}
$$

Verifica-se que o valor de $\left(\frac{\Delta K}{K}\right)_{T N L}$ para o pico de absorção apresenta valores praticamente coincidentes tanto para o $\mathrm{KCl}$ como para o $\mathrm{KBr}$.

A partir dos valores experimentais calculados para $\frac{\Delta K}{K}$ podemos determ 1 nar o valor do elemento de matriz $\left\langle 2 p_{z}|z| 2 s>\right.$, tanto para $0 \mathrm{KCl}$ como para 0 Kar.

0 valor desse elemento de matriz, de conformidade com as fórmulas II-11. ou II-21, è dedo por: 
$(\bar{z})^{2}=\left|<2 p_{z}\right| 2|2 s>|^{2}=0,36 \frac{\Delta k}{K}\left(\frac{w}{\varepsilon}\right)^{2}$

a valor calculado de $\frac{\Delta K}{K}$ deve sofrer as correçōes necessárias para levar em conta o fato de luz usada näo ser polarisada, deste modo, os valores devem ser corrigidos pelo uso de un fator igual à 2. Além disso para levar em con ta o efeito de modulaçäo dos sinais recebidos pelo "lock-1n" outra correçäo deve ser felta por melo do fator 1,27. Deste modo temos:

a) Paro o KCI:

$$
\begin{aligned}
& \frac{\Delta K}{K}=2 \times 1.27 \times 2.93 \times 10^{-5} \therefore \frac{\Delta K}{K}=7.44 \times 10^{-5} \\
& \therefore W=0.18 \mathrm{eV} .
\end{aligned}
$$

b) Para o KBr:

$$
\begin{aligned}
& \frac{\Delta K}{K}=2 \times 1.27 \times 2.85 \times 10^{-5} \therefore \frac{\Delta K}{K}=7.24 \times 10^{-5} \\
& B W=0.222 \mathrm{eV}
\end{aligned}
$$

Em primeira aproximaçäo vamos adotar em ambos os casos ( $K C l$ e KBr), para o valor de $\varepsilon$, campo elétrico local, o próprio valor do campo elétrico externo aplicado $f=4,5 \times 10^{4} \mathrm{~V} / \mathrm{cm}$.

Com esses elementos teremos:

$$
\begin{aligned}
& \bar{z}_{K C l}=2,06 \times 10^{-8} \mathrm{~cm} \\
& \bar{K}_{K B r}=2,52 \times 10^{-8} \mathrm{~cm}
\end{aligned}
$$

\section{IV.2. - DISCUSAO DOS RESULTADOS E CONCLUSOES.}

Considerando o valor do elemento de matriz obtido para o KCl, 1sto $\dot{8}$,

$$
\bar{Z}=2.06 \times 10^{-6} \mathrm{~cm} \text { a comparando este resultado com a prévisāo teóri- }
$$

ce :

$$
\bar{z}=3 a_{0}=3 \times 0,529 \times 10^{-8} \mathrm{~cm}=1,6 \times 10^{-8} \mathrm{~cm} \text { verifice-se que o va- }
$$
lor obt1do fol superior ao teórico, entretanto, nāo foi levado em conta que o 
campo local deve sempre ser major que o campo externo, o que permitirla diminuir o valor experimental e, talves, conduzi-1o à um valor mais pröximo do valor teórico.

Por outro lado, considerando-se os valores de $\frac{\Delta K}{K}$ para o $K C l$ e o $K B r$ verificamos que estes valores säo praticamente idēnticos. Como os dois cristais possuem em comum o ion alcalino. B como na primeira esfera de vizinhos mais próximos do centro $F$ estão situados os lons alcalinos, este fato parece su gerir que o comportamento do centro $F$ no efeito Stark está na dependência da na tureza dos ions que ocupam a primeira esfera dos lons mais próximos.

A concordância dos resultados obtidos para o $\mathrm{KCl}$ com aqueles já obtidos por Chlarotti indicam que o sistema em uso está funcionado adequadamente e pode rá ser empregado para o prosseguimento das pesquisas. A máxima sensibilidade atingida foi $\frac{\Delta K}{K}=1,5 \times 10^{-6}$ com resoluçäo em comprimento de onda de $3 \mu$.

IV.3. - SUGESTOZES PARA TRABALHOS FUTUROS.

19) Investigação sobre halogenetos de mesmo Ion alcalino:

a) Efeito Stark em KI afim de verificar se os resultados obtidos são iguais aos iguais aos do $\mathrm{KCI}$ e $\mathrm{KBr}$.

b) Efeito Stark em $\mathrm{NaCl}$ e $\mathrm{NaBr}$ afim de verificar se os respectivos resultados säo aproximadamente iguals.

$\left.2^{\circ}\right)$ Medida de efeito Stark em cristais mixtos tais $K C 1: K B r$, KCI:RbCl, etc, na previsão de que seja poseivel separar:os picos do efeito-cor respondentes à cada um cos ions alcalinos presentes.

$\left.3^{\circ}\right)$ Estudo do efeito Stark de $1^{a}$ e $2^{a}$. ordem de centros $Z$ em cristais mix tos.

$\left.4^{\circ}\right)$ Estudo do efeito Stark de centros $\mathrm{FU}_{2}$. 


\section{BIBLIOGRAFIA C I TA DA}

(1) A. W. Overhausser and H. Ruchardt, Phys. Rev.,112, 722 ( 1958 ).

(2) C. H. Henry, S. E. Schnatterly and C. P. Slichter, Phys. Rev, 137, A583 (1965).

(3) G. Chiarotti, U. M. Grassano, and R. Rose1, Phys. Rev. Letters , 17, 1043 (1966).

(4) H. Ivey, Phys. Rev., 72,341 (1947).

(5) B. S. Gourary and F. J. Adrian, Solid State Physics, 10, 127 (1960).

(6) J. H. Schulman anda W. D. Compton, Color Centers in Solids, (The MacMillan Co., Now York), (1962).

(7) J. J. Markham. F - Centers in Alkali - Halldes, Solid State Physics Suppl.0 (Academic Press, New York), (1966).

(8) Fowler, W. B., in Prysics of Color Centers, edited hy $\%$. B. Fowler, (Academic Press. Inc., New York), (1958)

(9) J. H. Van Vleck, Phys. Rev., 74, 1168, (1948).

(10) M. Lax, J. Chem. Phys,, 20, 1752, (1952). 
LEGENDAS DAS FIGURAS

Figura 1 - Banda $F$ e absorção correspondente em um cristal de $\mathrm{KBr}$ colorido aditivamente.

Figura 2 - Representação esquemätica dos orbitais não perturbados correspon dentes aos estados $2 s$ e $2 p$ do centro $F$.

Figura 3 - Representação esquuemática dos orbitais perturbados correspondentes aos estados $2 s$ e $2 p$ do centro $F$.

Figura 4 - Representaçäo esquemática dos niveis de energia dos estados pertur bados e não perturbados do centro $F$.

Figura 5 - Curvas obtidas por Chiarotti e outros referentes :

a) Variação do coeficiente de absorção região das bandas $K$ e $F$ devidas à aplicação de un campo. elétrico externo i. de $45 \mathrm{kV}$ (peak) $/ \mathrm{cm}$.

b) Dependência entre a variação relativa do coeficiente de absor ção, referente ao máximo da banda F, o quadrado da intensidado do campo elétrico externo aplicado.

Figura 6 - Esquena de montagim do sistema.

Figura 7 - Orientação do campo elétrico aplicado, $\vec{E}$, direção de propagação da luz, $\bar{K}$, e plano de polarisação da luz para o qual é produzido efeito Stark no centro F. A porção hachuriada representa a localisa ção dos centros de cor.

Figura 8 - Detalhe do portador de amostra do criostato.

Figura 9 - Curva de absorção, na temperatura ambiente, da amostra de KCl uti11.sada.

Figura 10 - Curva de absorção, na temperatura ambiente, da amostra de KBr uti1isada.

Figura 11 - Dados experimentais típicos mostrando a reprodução do registro ob- 
tido- para o ofeito stark do centro F em KCl.

Figura 12 - Dados experimentais tipicos, mostrando a reprodução do registro ob tido para o efeito Stark do centro $F$ em KEr.

Figura 13 - Resultados experimentals obtidos para o efelto Stark do centro $F$ en KCl.

Figura 14 - Resultados experimentals obtidos para o efeito Stark do centro $F$ em $\mathrm{KBr}$.

Figura 15 - Resultados experimentals mostrando a dependéncla entre a varieçäo relativa do coeficiente de absorção, referente ao mäximo da bendo F. e o quadrado da Intensidade do campo elétrico externo aplicedo.

Figura 16 - Reproduçäo da figura 3-5 do livri de Schulman e Compton (6). que mostra a dependência entre a meia largura $W$ da banda $\mathrm{F}$ en $\mathrm{NaCl}, \mathrm{KBr}$ e KI, en funçăo da varlaçāo de temperatura. 


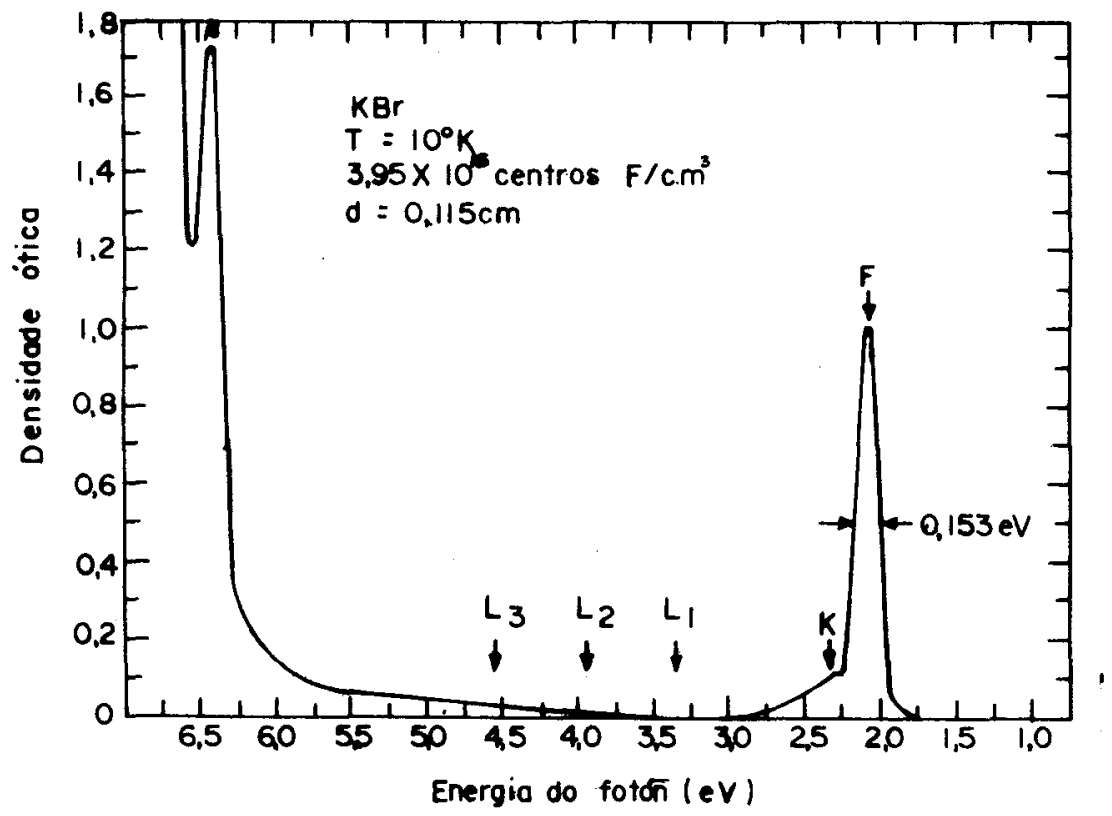

F IG. I 

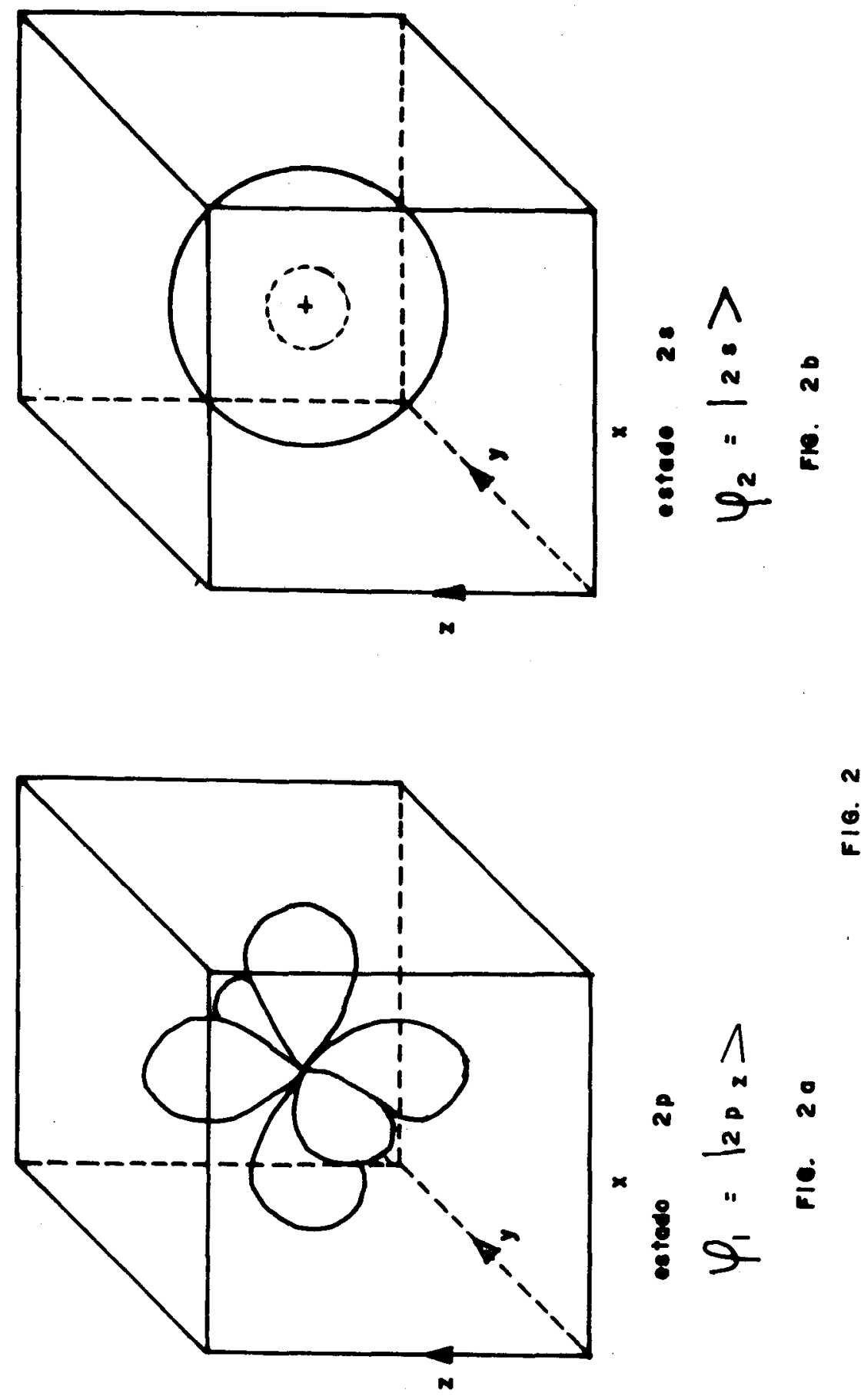

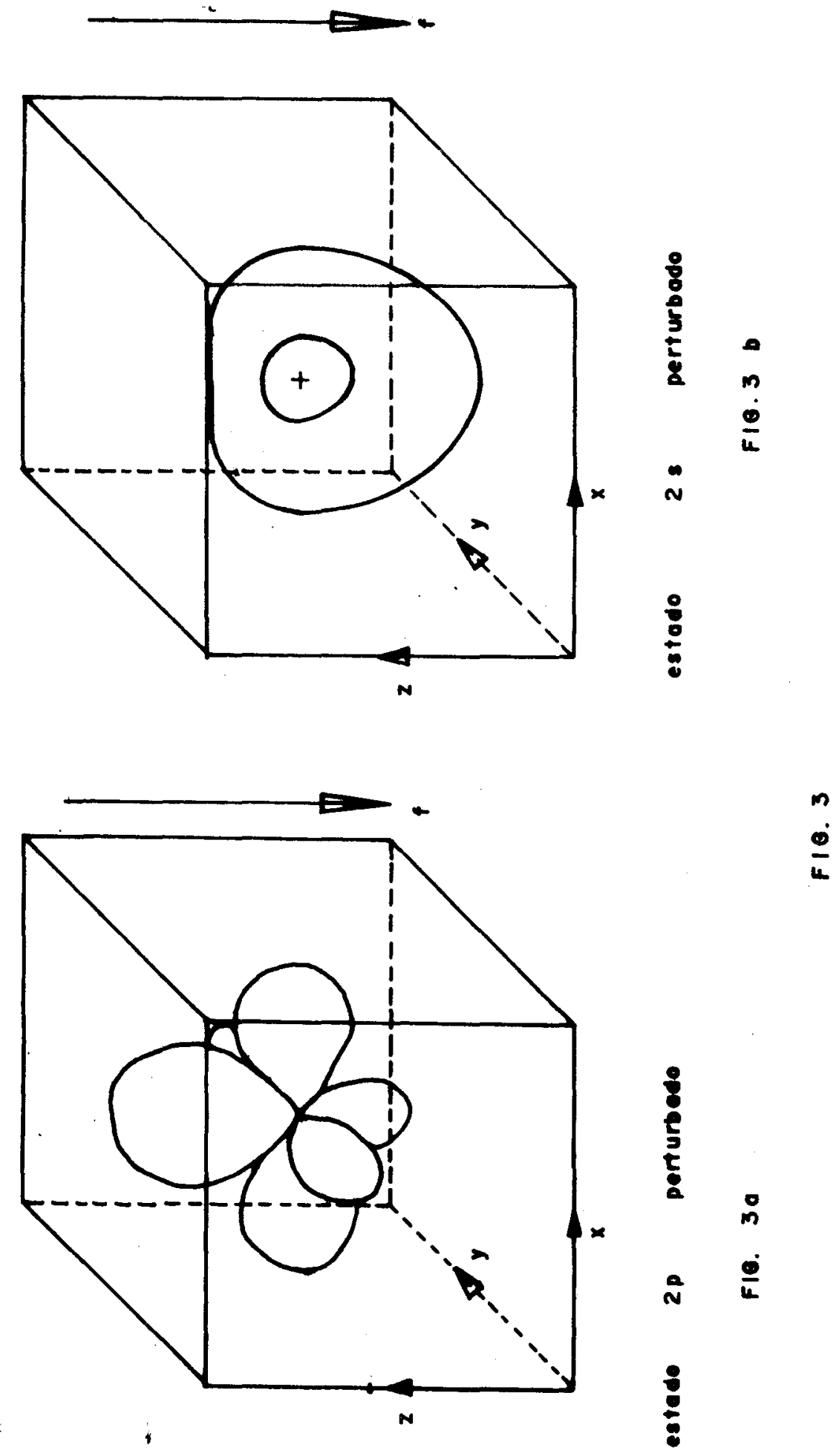

8

a

N $\frac{\dot{\theta}}{4}$

8 


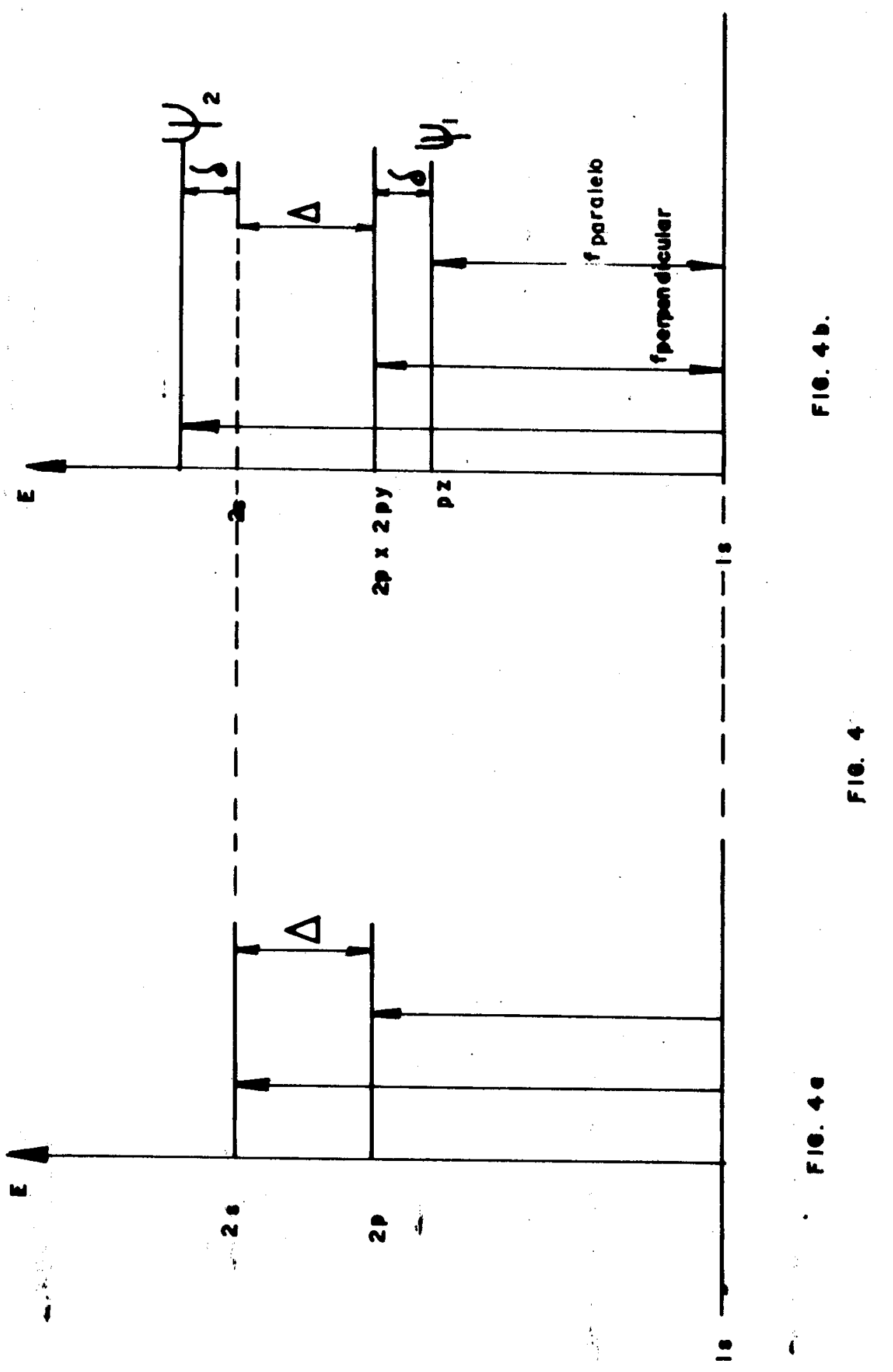




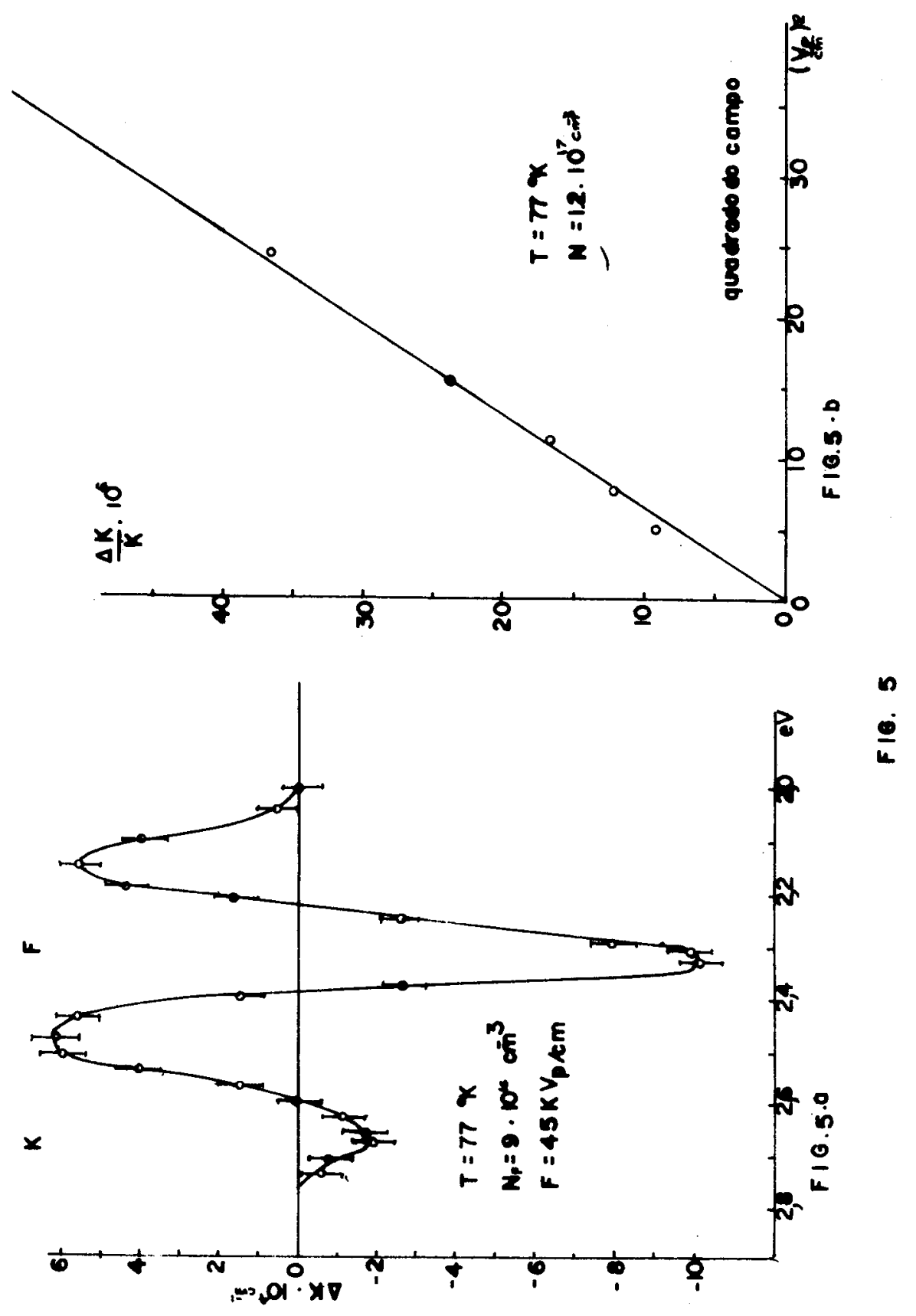




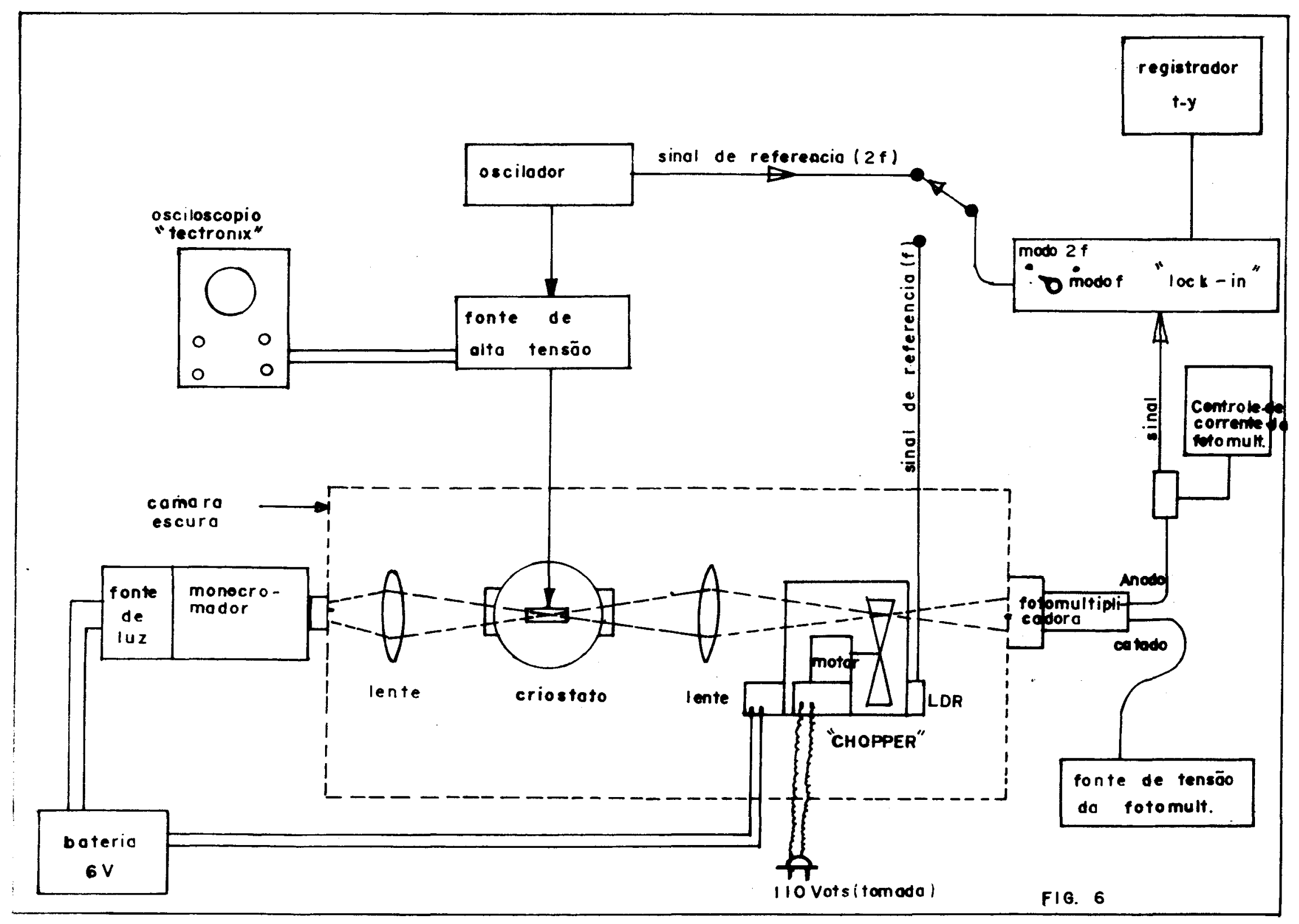



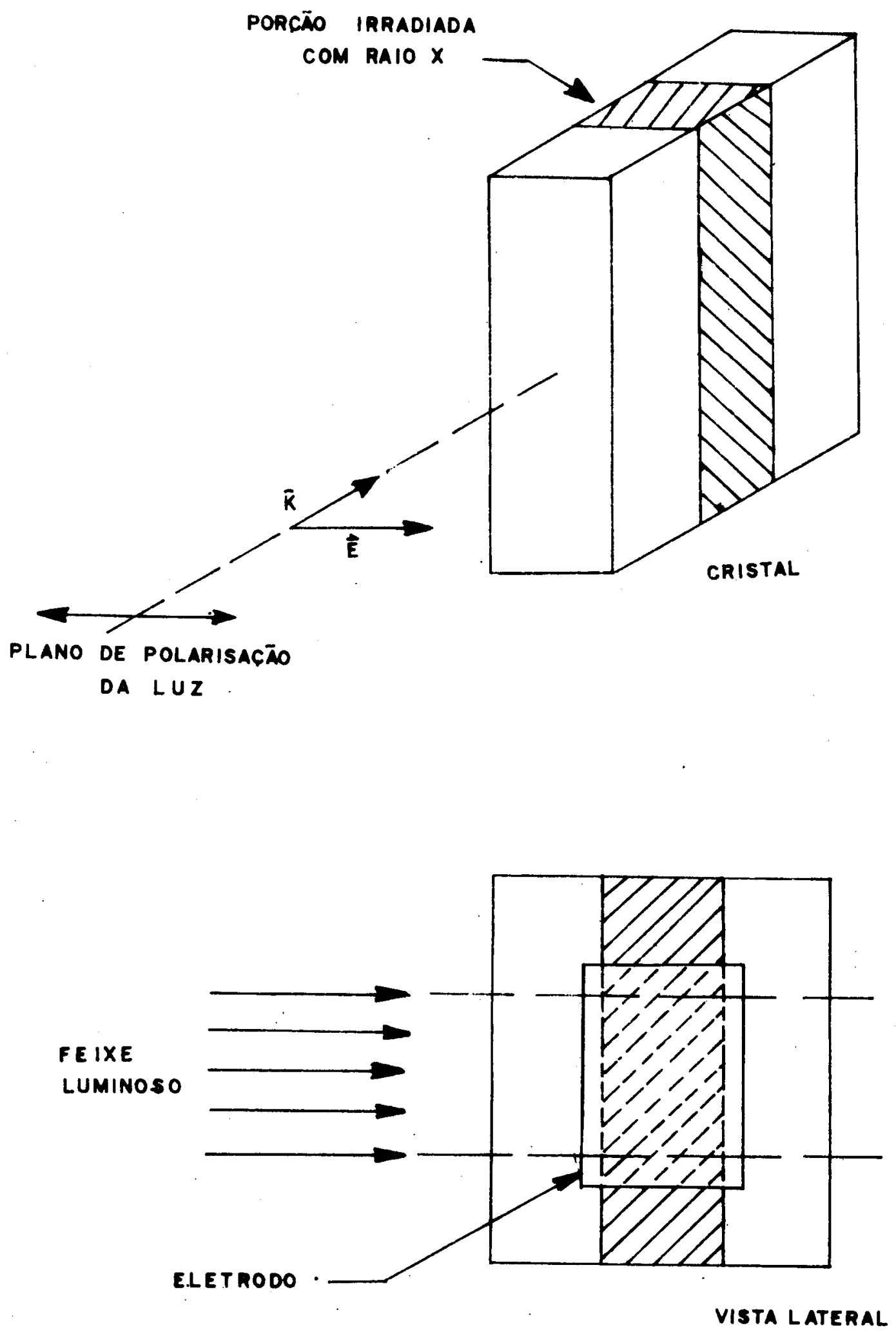

Fie. 7 

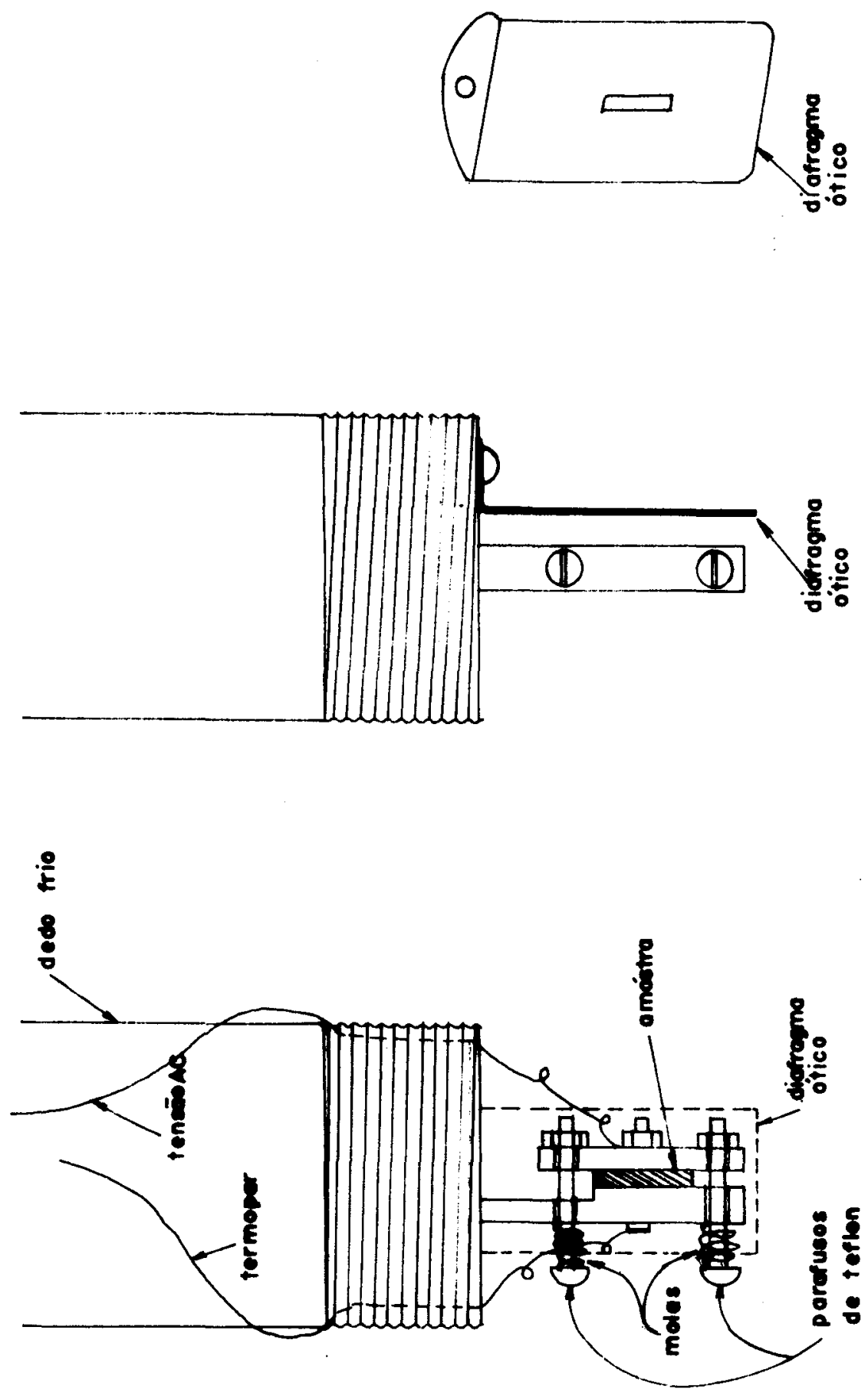

อง 


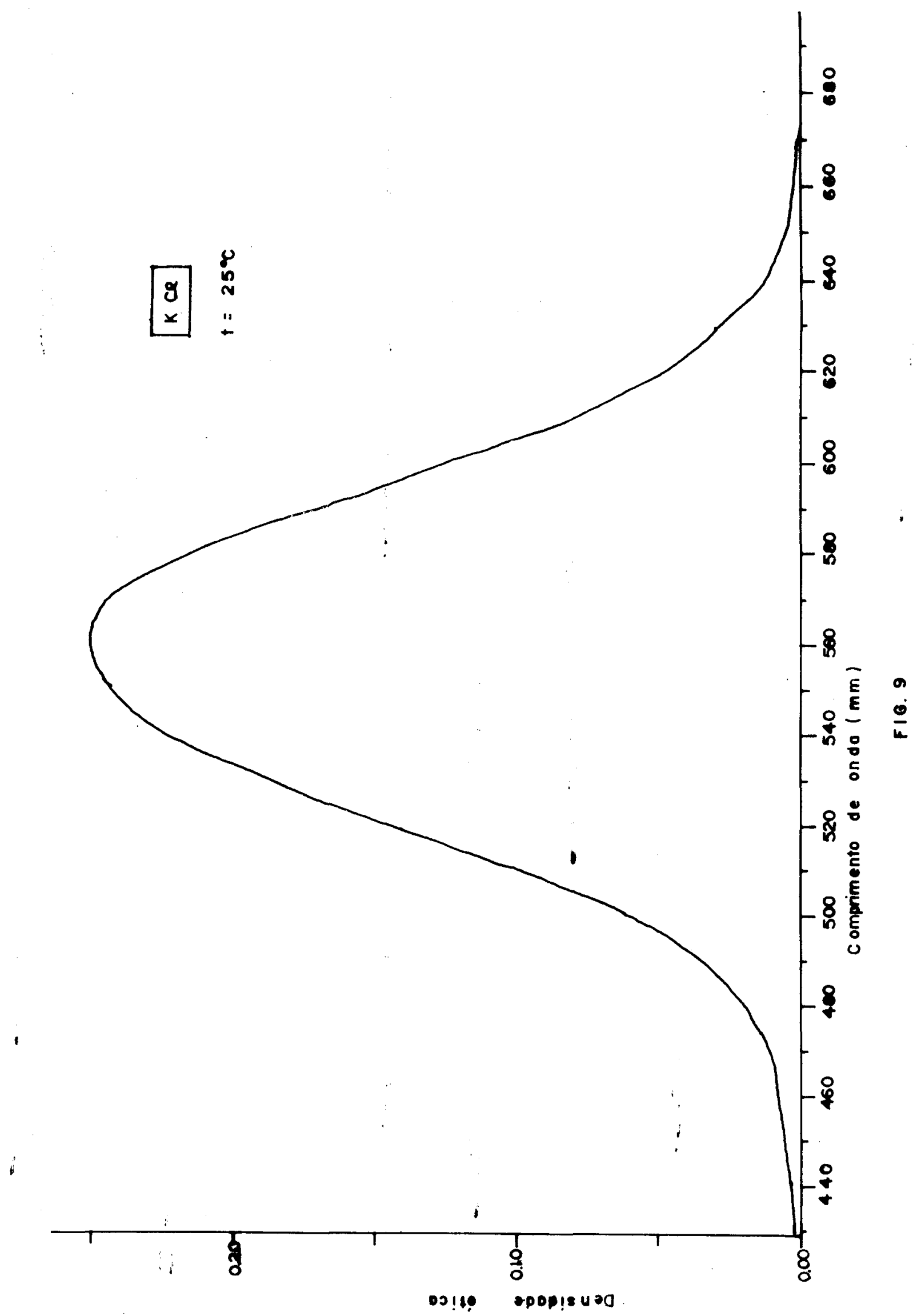




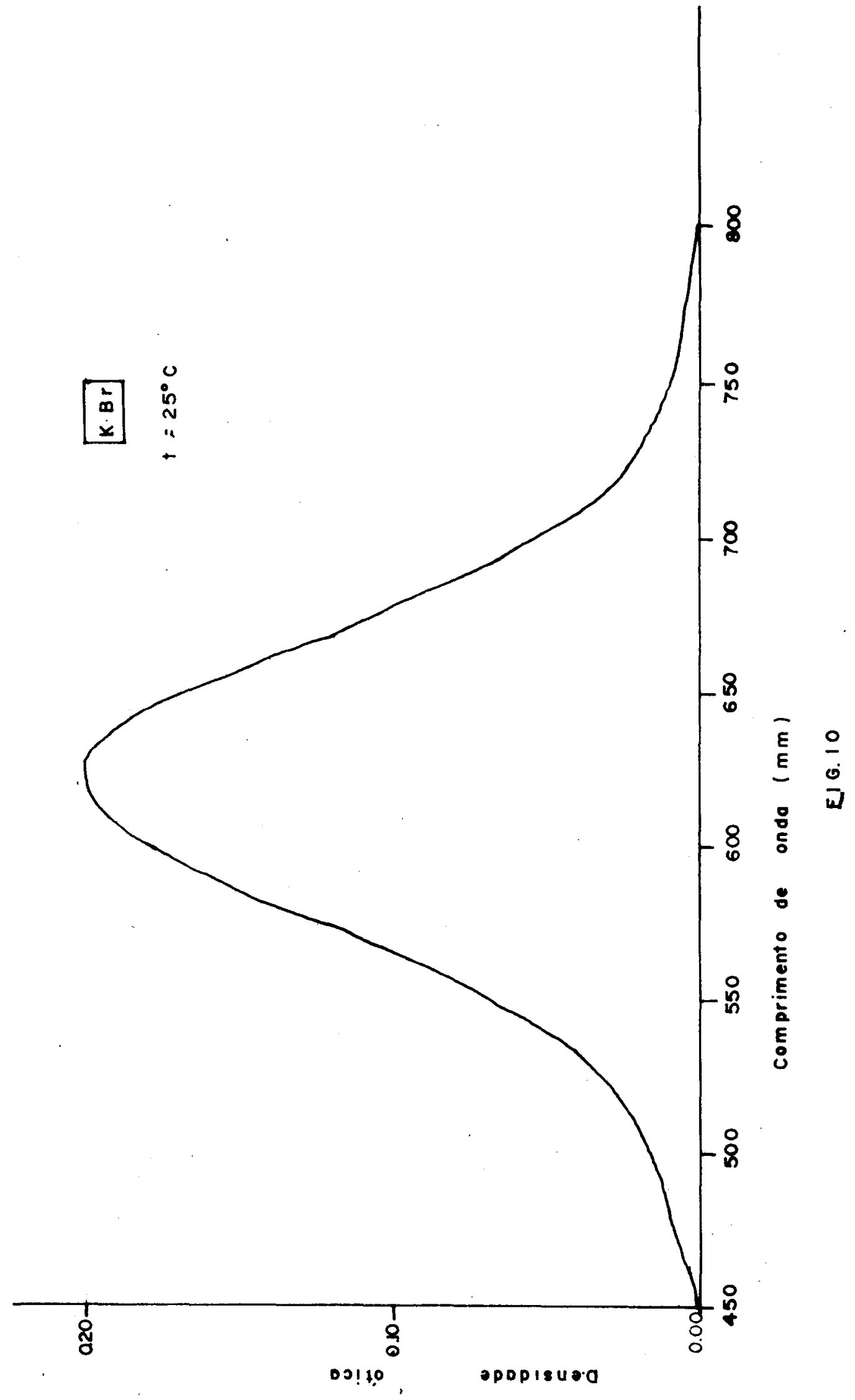




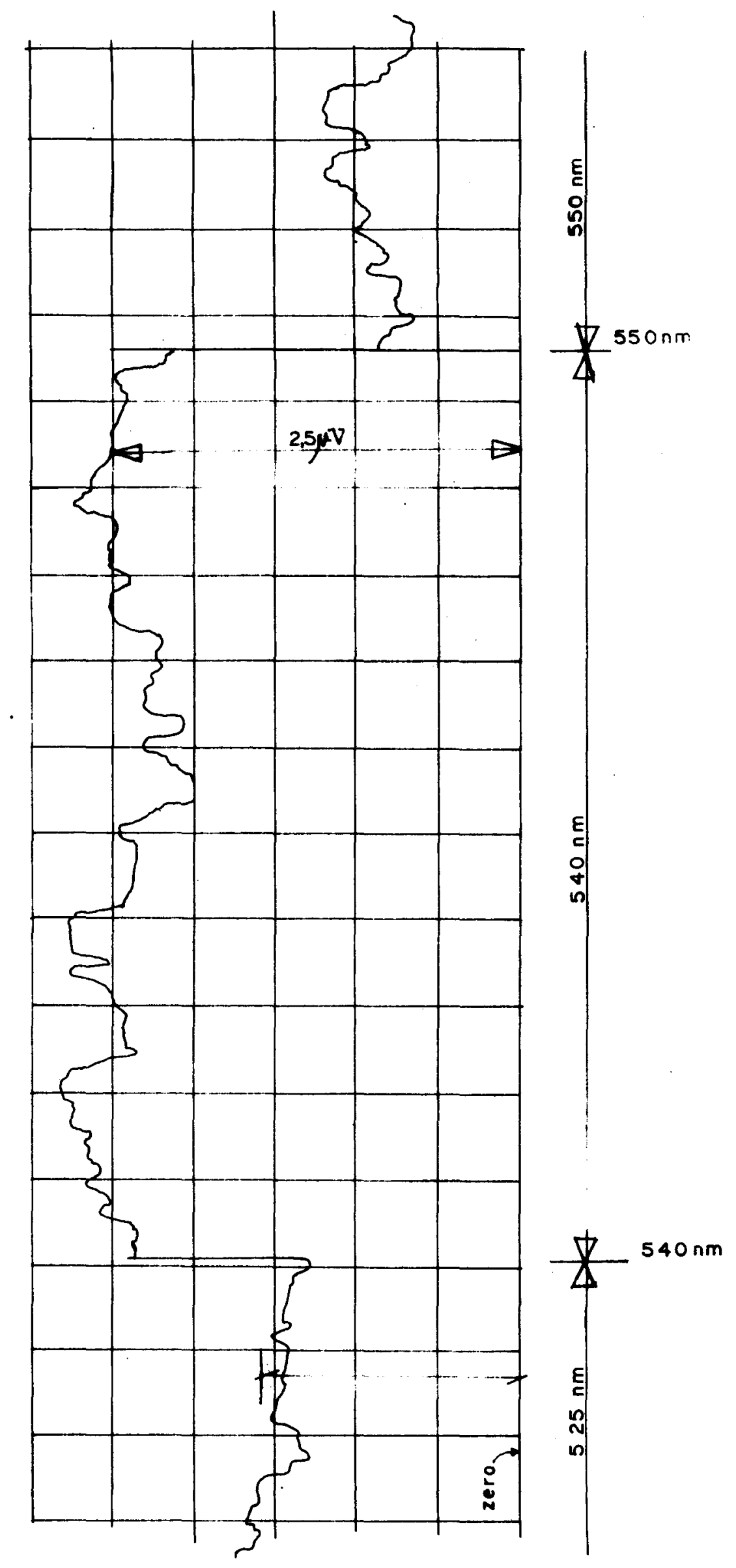

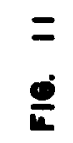




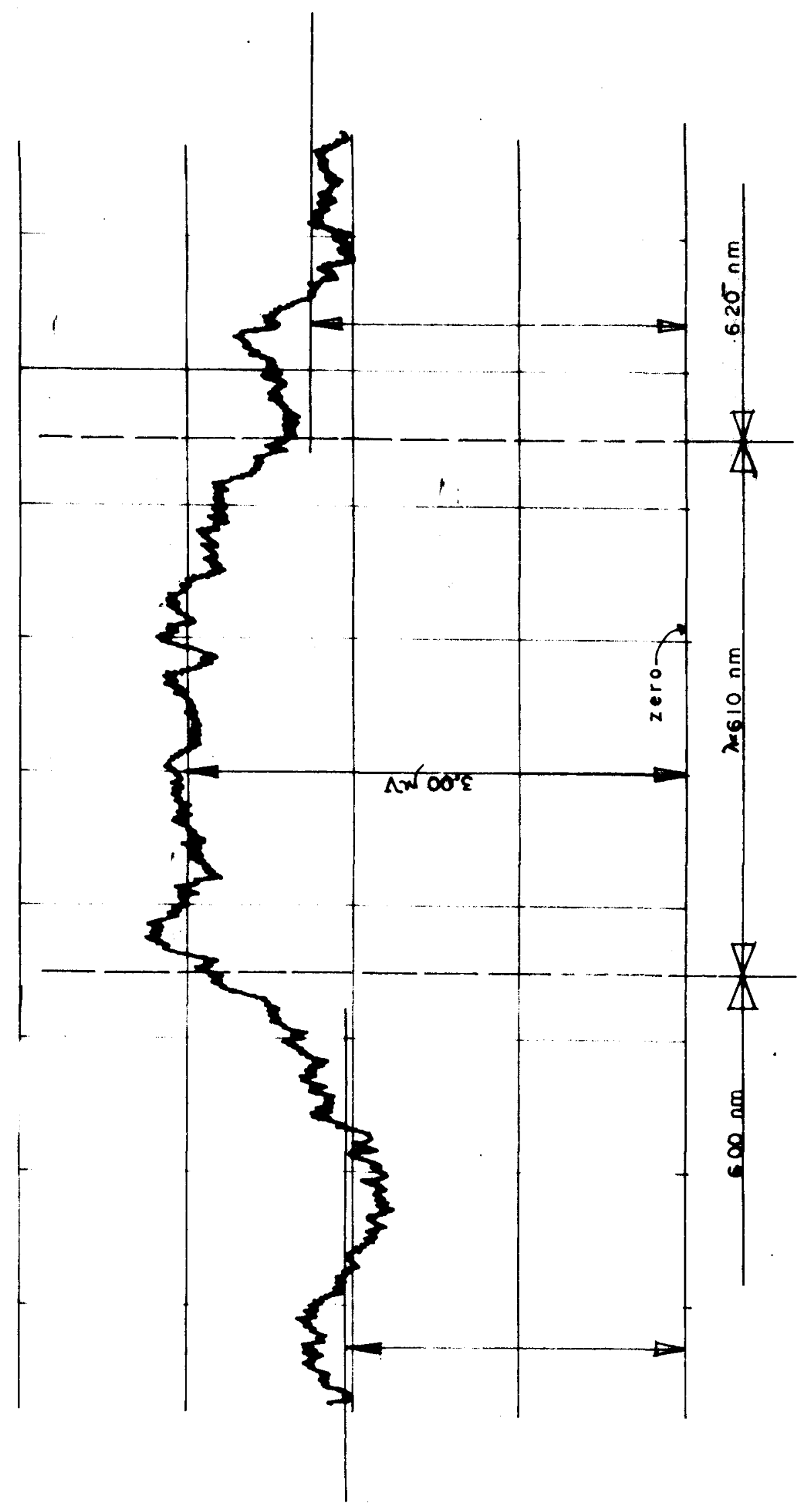

2
1 


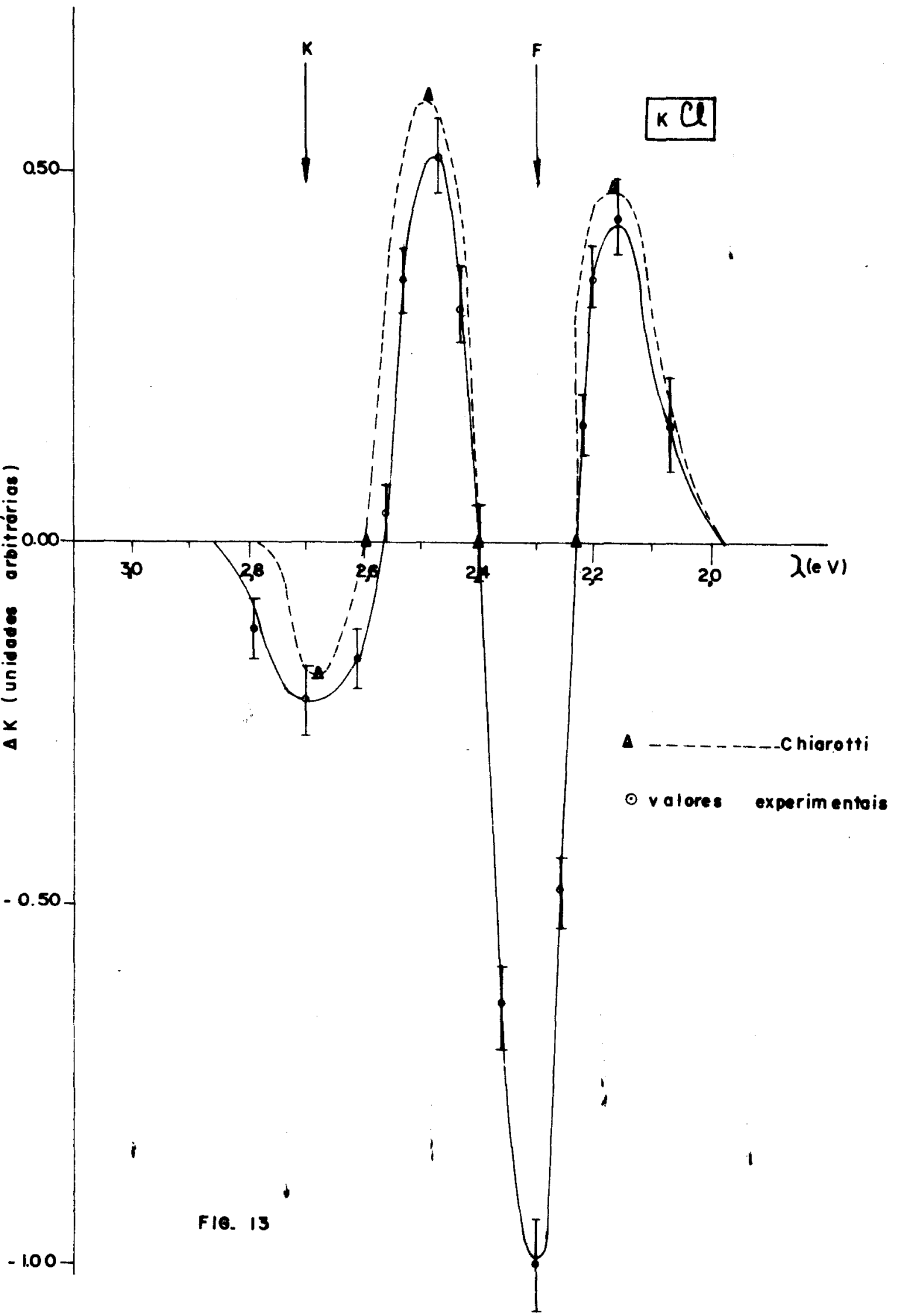




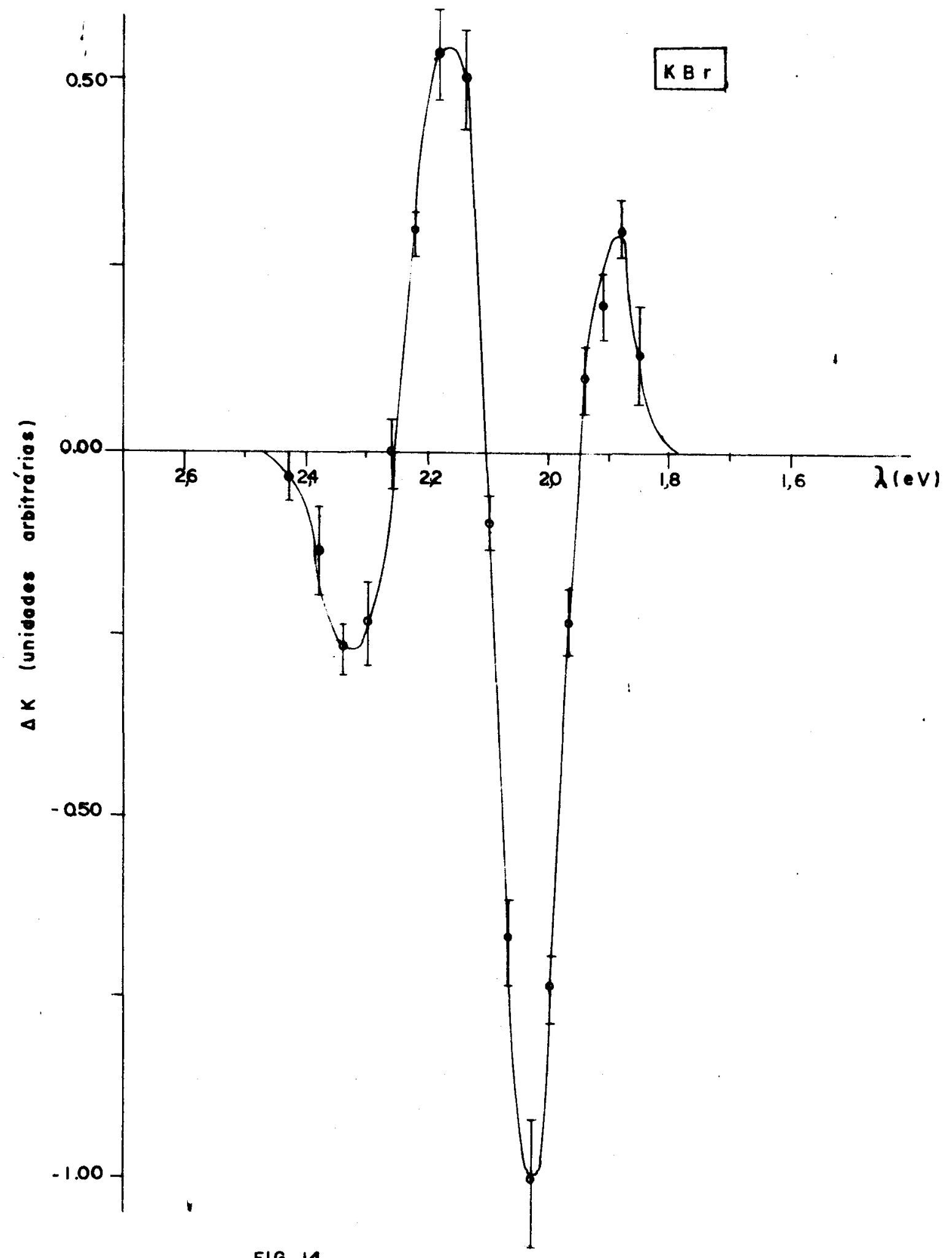

FIG. 14 


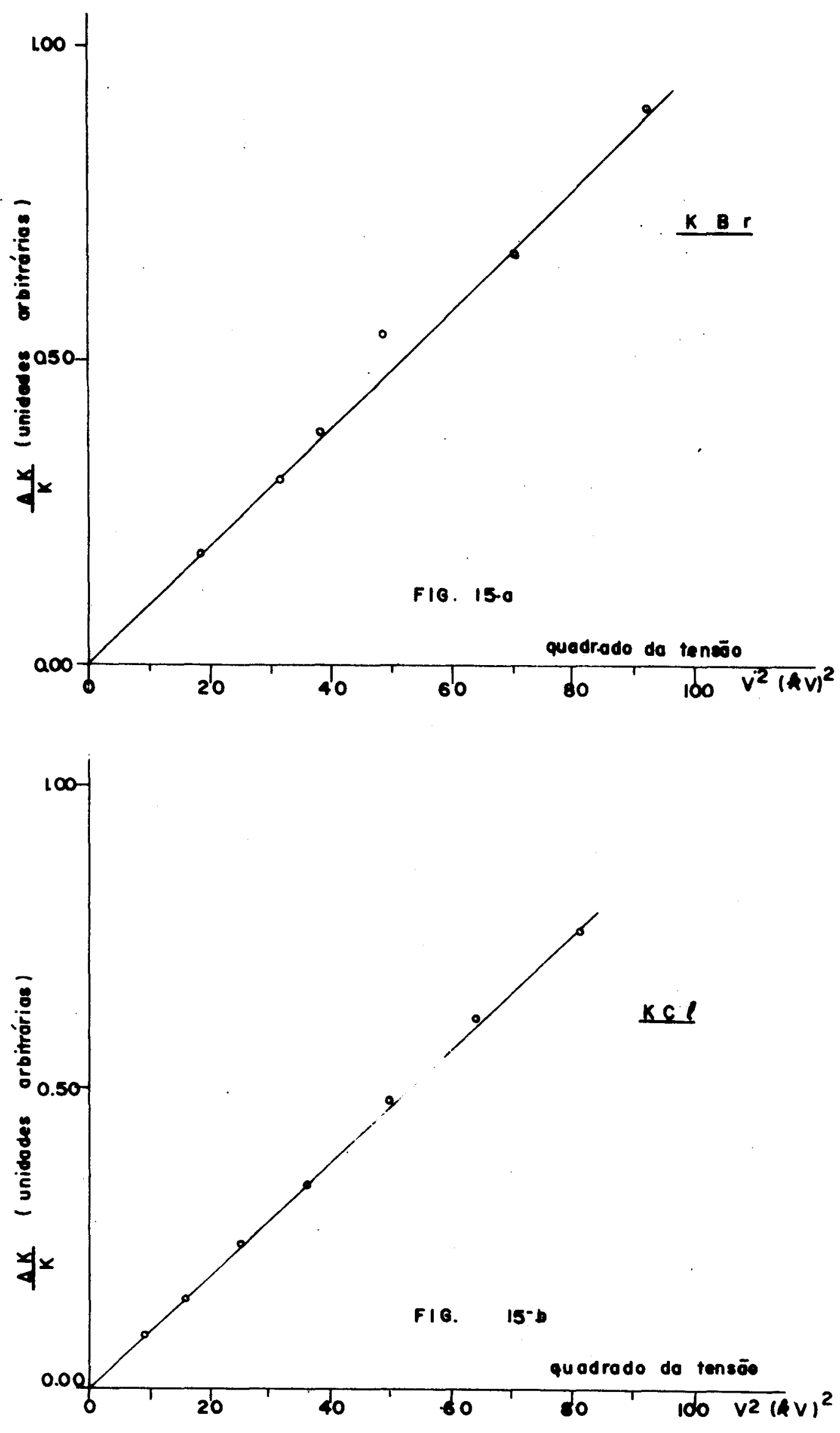

F16. 15 


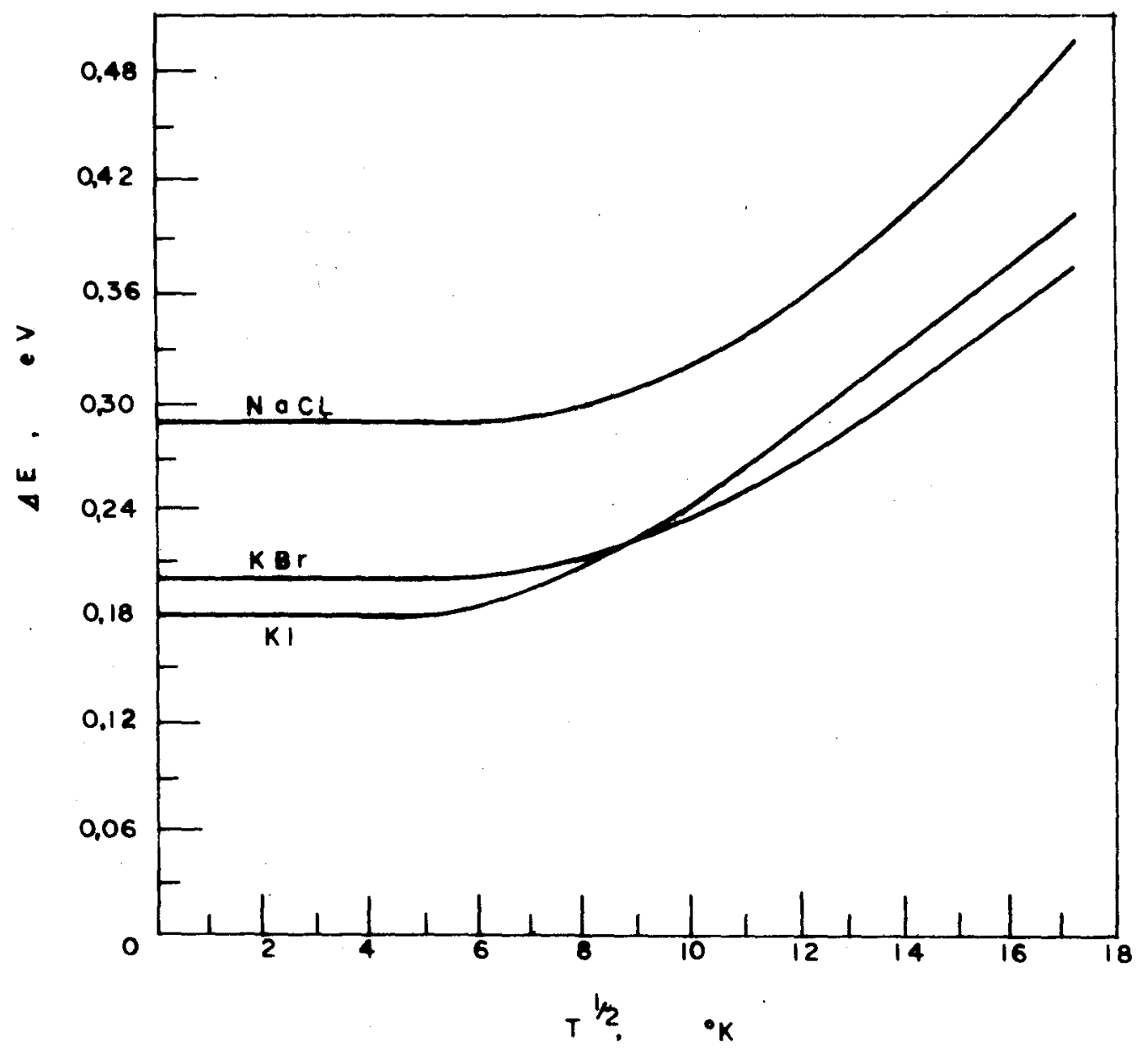

FIG. 16 